\title{
An Experimental Study on the Use of Fonio Straw and Shea Butter Residue for Improving the Thermophysical and Mechanical Properties of Compressed Earth Blocks
}

\author{
Etienne Malbila1,2*, Simon Delvoie ${ }^{3}$, David Toguyeni' ${ }^{2}$, Shady Attia ${ }^{4}$, Luc Courard ${ }^{3}$ \\ ${ }^{1}$ Laboratory of Thermal and Renewable Energy (LETRE), University Joseph KI-ZERBO, Ouagadougou, Burkina Faso \\ ${ }^{2}$ Laboratory of Physics and Chemistry of the Environment (LPCE), University Joseph KI-ZERBO, Ouagadougou, Burkina Faso \\ ${ }^{3}$ Laboratory of Building Materials (LMC), University of Liège, Liège, Belgium \\ ${ }^{4}$ Sustainable Building Design Lab (SDB Lab), University of Liège, Liège, Belgium \\ Email: *t.emalbila@gmail.com
}

How to cite this paper: Malbila, E., Delvoie, S., Toguyeni, D., Attia, S. and Courard, L. (2020) An Experimental Study on the Use of Fonio Straw and Shea Butter Residue for Improving the Thermophysical and Mechanical Properties of Compressed Earth Blocks. Journal of Minerals and Materials Characterization and Engineering, 8, 107-132.

https://doi.org/10.4236/jmmce.2020.83008

Received: February 12, 2020

Accepted: May 12, 2020

Published: May 15, 2020

\section{Copyright (C) 2020 by author(s) and} Scientific Research Publishing Inc. This work is licensed under the Creative Commons Attribution International License (CC BY 4.0).

http://creativecommons.org/licenses/by/4.0/

\section{Open Access}

\section{Abstract}

The efficient use of building materials is one of the responses to increasing urbanization and building energy consumption. Soil as a building material has been used for several thousand years due to its availability and its usual properties improving and stabilization techniques used. Thus, fonio straws and shea butter residues are incorporated into tow soil matrix. The objective of this study is to develop a construction eco-material by recycling agricultural and biopolymer by-products in compressed earth blocks (CEB) stabilization and analyze these by-products' influence on CEB usual properties. To do this, compressed stabilized earth blocks (CSEB) composed of clay and varying proportion (3\% to $10 \%)$ of fonio straw and shea butter residue incorporated were subjected to thermophysical, flexural, compressive, and durability tests. The results obtained show that the addition of fonio straw and shea butter residues as stabilizers improves compressed stabilized earth blocks thermophysical and mechanical performance and durability. Two different clay materials were studied. Indeed, for these CEB incorporating 3\% fonio straw and $3 \%-10 \%$ shea butter residue, the average compressive strength and three-point bending strength values after 28 days old are respectively $3.478 \mathrm{MPa}$ and 1.062 MPa. In terms of CSEB thermal properties, the average thermal conductivity is $0.549 \mathrm{~W} / \mathrm{m} \cdot \mathrm{K}$ with $3 \%$ fonio straw and from 0.667 to $0.798 \mathrm{~W} / \mathrm{m}$. $\mathrm{K}$ is with $3 \%-10 \%$ shea butter residue and the average thermal diffusivity is 1.665.10 $0^{-7} \mathrm{~m}^{2} / \mathrm{s}$ with $3 \% \mathrm{FF}$ and $2.24 .10^{-7} \mathrm{~m}^{2} / \mathrm{s}$ with $3.055 .10^{-7} \mathrm{~m}^{2} / \mathrm{s}$ with $3 \%$ $10 \%$ shea butter residue, while the average specific heat mass is between 1.508 
and $1.584 \mathrm{~kJ} / \mathrm{kg} \cdot \mathrm{K}$. In addition, the shea butter residue incorporated at $3 \%$ $10 \%$ improves CSEB water repellency, with capillary coefficient values between 31 and $68\left[\mathrm{~g} / \mathrm{m}^{2} \cdot \mathrm{s}\right]^{1 / 2}$ and a contact angle between $43.63^{\circ} \mathrm{C}$ and $86.4^{\circ} \mathrm{C}$. Analysis of the results shows that, it is possible to use these CSEB for single-storey housing construction.

\section{Keywords}

Fonio Straw, Shea Butter Residue, Stabilization, Compressed Stabilized Earth Blocks, Thermophysical and Mechanical Properties

\section{Introduction}

The construction industry has always exploited natural and/or manufactured resources to meet development needs. The use of materials derived from concrete and its derivatives has gradually become necessary for reasons of properties and modernity in relation to local materials, particularly in sub-Saharan Africa. However, M. Ouedraogo et al. (2019) [1] point out that the construction of concrete habitats is costly in developing countries and has a high level of environmental impact. Materials such as cement block are usually used in Sub-Saharan African countries, such as Burkina Faso in the context of socio-economic housing construction projects. However, at this level, the use of stabilized or unstabilized compressed earth blocks (CEBs) is not yet explored, while the development of local secondary natural resources, often considered as waste, is a more explored research area for construction ecomaterials development. Whereas according to Fetra Venny Riza et al. (2010) [2] Compressed Stabilized Earth Brick (CSEB) gives the view of energy-efficient, cost reduction and environmentally-friendly building materials, overall contribution on the sustainable development.

Although earthen construction is usually profitable, its economic benefits depend on the nature and amount of binder used in the stabilization process [3]. Several researches have been undertaken to find alternative solutions for habitat construction. Plant aggregates and straw (Cereal straws, Wood aggregates, Bast straw, Palm tree straw, Waste and residues, Leaf straw, Aquatic plant straw and chips. Sheep wool) have been incorporated into the earth matrix in the aim of enhancing performance for thousands of years but scientific studies began quite recently. A. Laborel-Préneron et al. (2016) [4] and A. Compaore et al. (2017) [5] show that the use of local construction materials (BTC, BLT, adobes) makes it possible to obtain better thermal performance of the building compared to modern materials.

For many reasons (heritage, ecological, economic, proximity...), construction materials that have been used by humans for thousands of years, such as earth and/or bio-based materials (wood, straw and plant aggregates) are being reconsidered as pertinent materials [4]. We note that the choice of stabilizers depends 
on availability in the region and performance. In Burkina Faso, research has focused on the use of straw [6], hibiscus straw [7] [8], cellulose [9] and nere chips [10] whose incorporation into the soil material improves the composite thermophysical and mechanical properties for housing construction. The performance of the composite thus benefits from the straw and matrix [11]. A recent study in this field is the one conducted by M. Ouedraogo et al. (2019) [1] which shows that fonio-straw-reinforced adobes have interesting properties for use as cheap construction materials in the Sahelian zones and could contribute significantly to the thermal comfort of the inhabitants in this hot climate.

In the production of fonio and shea butter, many residues are produced and application in the construction industry is not sufficiently explored in the value chain of these agricultural and forestry by-products. According to APFL (2011), each part of the shea has a particular use and its value chain contributes to $0.60 \%$ of GDP to Burkina Faso's economy. For example, vegetable straw have been used for a very long time, either alone, for example for the production of textiles or ropes, or in combination with another material. But the incorporation of shea butter residues into earth matrix to reinforce thermo-physical and mechanical properties has not yet been explored at the scientific level.

CSEB give the view of energy efficient, cost reduction and environmentally friendly building materials, overall contribution on the sustainable development [2]. Therefore, the evaluation and characterization of their constituents play an important role in the development of effective and sustainable adobe building materials [12]. In this context, the aim of our study is to contribute to agricultural and biopolymer by-products valorization in soil blocks stabilization for sustainable construction. It presents the results of thermo-physical, mechanical properties and durability characterization of CSEB incorporated in varying ratio by fonio straw and shea butter residue.

The analysis of the results obtained will focus on the possibilities of using these new composite materials in housing construction in the sahel region, where energy and urbanization constraints are increasing. As everywhere in the world, in this sub-Saharan Africa area, the efficient and innovative use of building materials is necessary to achieve important environmental objectives [13]. This study complements the one conducted by Moussa Ouedraogo et al. (2019) [1] both in the process and by exploring the optimization of the proportions of fonio straw incorporations in the soil matrix for construction in the Sahel region. This study also introduces reflection on the use of shea butter residue in soil stabilization as a building material. We will be able to exploit the results of other research projects such as those conducted as part of the PaTerre+ project by researchers from the CRAterre-ENSAG laboratory and the LRMH, have worked on the possibility of classifying stabilizers of animal or plant origin and to develop protocols to measure the performance, durability and compatibility of protective coatings made of stabilized soil using biopolymers [14] [15].

There is a wide variety of earth materials and natural straw used as stabilizers for compressed earth blocks used in construction. Natural straw can be of vege- 
table, animal or mineral origin. According to B. Taallah \& A. Guettala (2016) [16] palm straw lead to a reduction in thermal conductivity and bulk density and increases the capillary absorption of the blocks. In this study, the materials used for Compressed Stabilized earth block were two clay materials (called Adina 1 and Adina 2, as matrix (Figure 1) and agricultural (fonio straw) and biopolymer (shea butter residue) by-products as stabilizers (Figure 1).

The soil and fonio straw used were taken from a site in Dina (Burkina Faso) and the two types of shea butter used were taken in Dedoudou and Lena (Burkina Faso). Fonio straw are secondary resources derived from agricultural and non-timber forest products. We have two types of shea butter residues: grey (from Lena) and reddish (from Dedougou). Fonio straw are by-products, currently used as animal bedding, as a substrate in agricultural soils or as a stabilizer in construction with the soil material. As for shea butter residues, they are also used as a stabilizer for the construction of crop storage granaries. In addition, we used quicklime with fonio straw to double stabilize some of the CSEB studied. All these materials are characterized by their availability, inexpensive and abundance in Burkina Faso area.

The population increase in Burkina Faso and rapid urbanization and housing construction increases the consumption of natural resources. To meet the demand for housing, many urbanization projects are being undertaken without succeeding in absorbing the ever-increasing need. Indeed, according to the RGPH, 2006 in terms of urbanization, nearly $31.3 \%$ of the population will live in cities in 2020 (INSD 2009). In this context, this study will contribute to alternative solutions to meet housing and energy constraints with the design of accessible building eco-materials in rural and peri-urban areas.

\section{Materials and Methods}

This study is completely experimental and to this end we have established a conceptual framework for a descriptive study of our working methodology based on the work of [12] [16] [17]. As shown in Figure 2, our methodology identifies three main areas that will be described in the following paragraph.
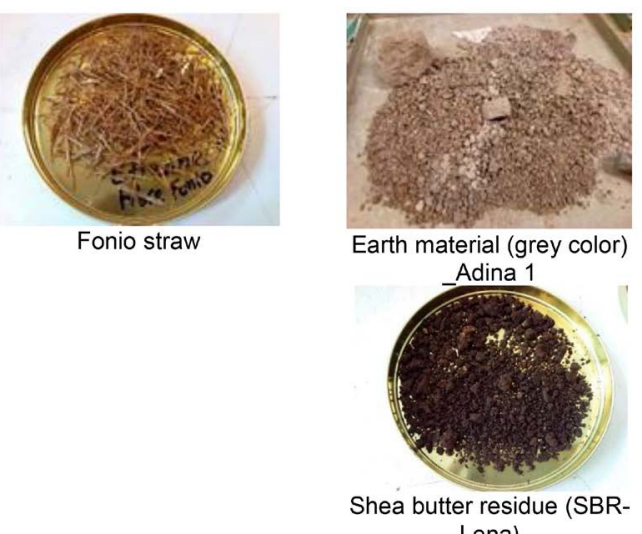

Lena)

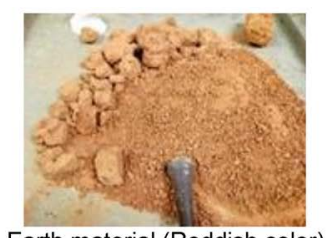

Earth material (Reddish color)

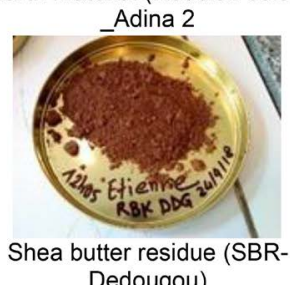

Figure 1. Earth material and stabilizers specimens. 


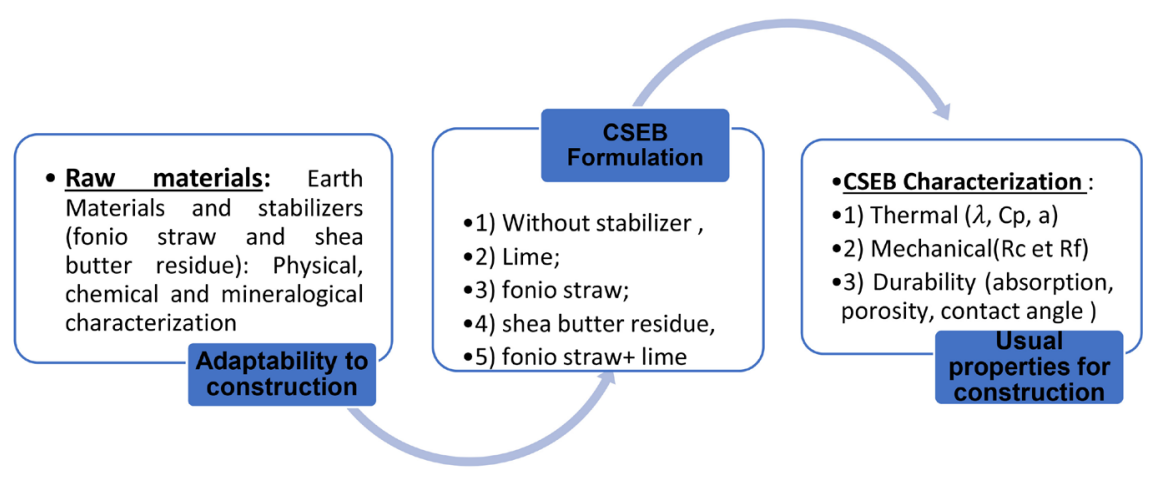

Figure 2. Study conceptual framework.

\subsection{Raw Materials Characterization}

Due to their significant heterogeneity, earth materials were characterized in order to ensure their suitability to the production of CSEB [18]. This characterization concerns the identification of earth materials through physical, chemical and mineralogical tests. Table 1 presents the mineralogical composition of earth materials obtained by the X-ray diffraction (XRD) analysis method on the fine fraction (fraction $<2 \mu \mathrm{m}$ ). With these XRD results, it is possible to appreciate the materials susceptibility to swelling.

These values are accurate to within $\pm 5 \%$ (for the first part of the major mineral phases: quartz, kaolinite, K-Feldsp and Plagio) using the semi-quantitative method. The distribution of grain size of soil carried out according to NF P 18-560 and NF P 94-57 standard is displayed in Figure 3. The Atterberg limits done according to NF P 94-512-12 (or NF P 94-051 XP CEN ISO/TS 17892-12), yielded a limit liquid of 22.64 and 25.03 and a plasticity index of 10.96 and 9.02 respectively for Adina 1 and Adina 2.

For both types of soils, a methylene blue value obtained was 3 according to Standards NF EN 933-9, NF P 94-068, NF P 18-592. At the structural level, Adina 1 is sandy clay with $72 \%$ sand, $16 \%$ clay and $11 \%$ silt and Adina 2 is sandy silt with $59 \%$ sand, $21.2 \%$ silt and $18.8 \%$ clay. Their specific weights of the grains obtained by the Gas Pycnometer test according to standard NF P 94-512-3 are respectively 2.66 and $2.73 \mathrm{kN} / \mathrm{m}^{3}$ and dry densities of 1.87 and 1.91 .

For the present work, the fonio straw were cut before being introduced into the matrix but the shea butter residues were used as they were. For fonio straw, their biochemical compositions were addressed in a previous study by [1] and they contain quasi-crystalline cellulose and hemicelluloses.

These different results show that the two materials were situated in Casagrande abacus zone A1 (Figure 4) and can be used as a building material to formulate compressed earth bricks.

However, given clay rates fractions and activity limits, it was important to study the CSEB durability. According to Agus Setyo Muntohar (2003) [19] the swelling behavior of expansive soils often causes unfavorable problems, such as differential settlement and ground heaving. Several rheological studies have established that clay soils swelling is the main cause of instability in civil engineering 
Table 1. Mineralogical composition of the soils studied (in \%).

\begin{tabular}{cccccccccc}
\hline Type of material & \multicolumn{2}{c}{ Quartz } & Kaolinite K-Feldsp & Anatase & Illite & Goethite & Plagio & Smectite \\
\hline Adina1 & 75 & 13 & 8 & 1 & 2 & 0 & 0 & 1 \\
Adina 2 & 71 & 15 & 5 & 1 & 3 & 5 & 0 & 0 \\
Aboudry & 49 & 15 & 14 & 1 & 4 & 0 & 8 & 8 \\
Anouna & 39 & 43 & 5 & 5 & 0 & 0 & 5 & 3 \\
\hline
\end{tabular}

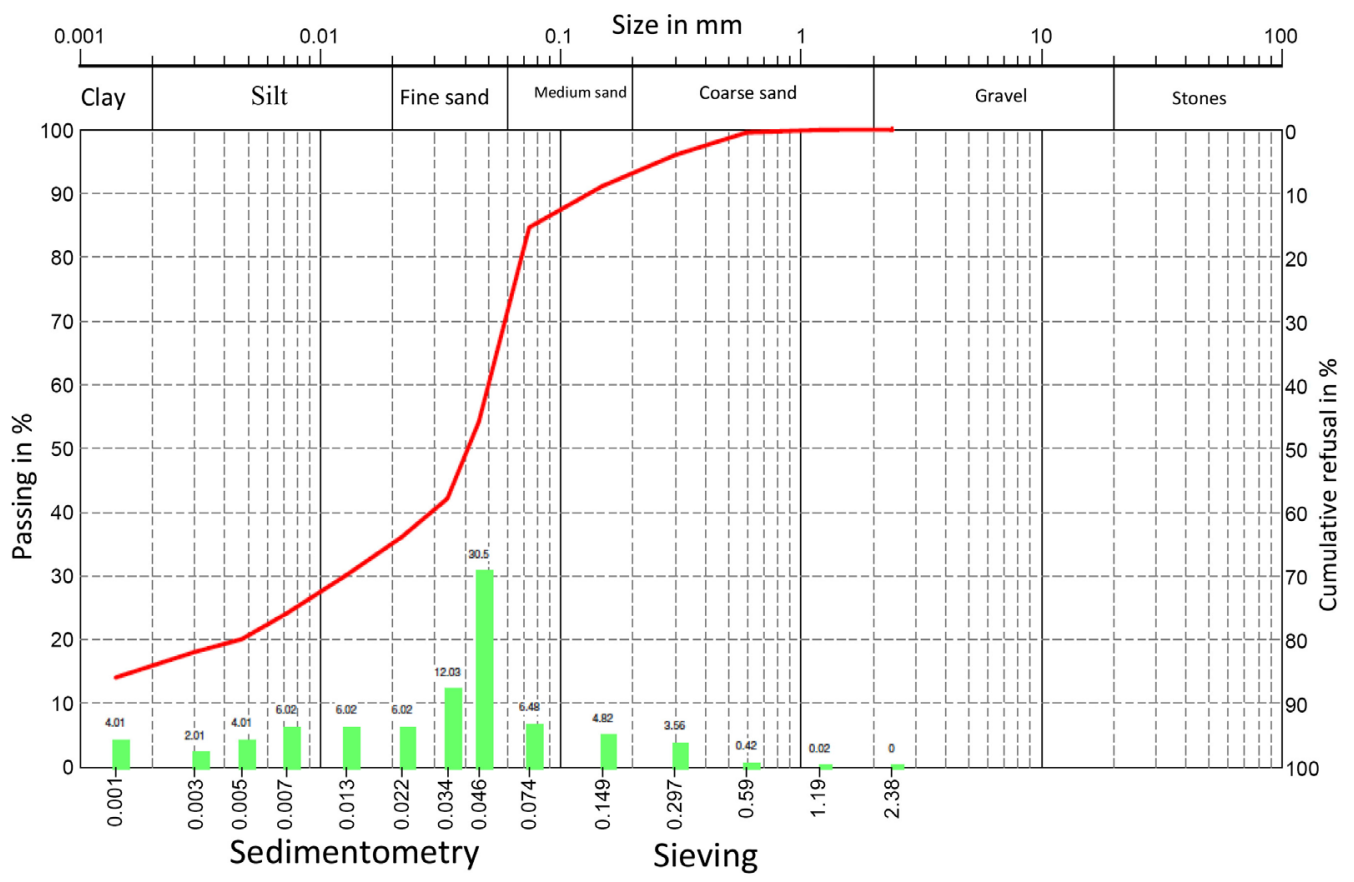

(a)

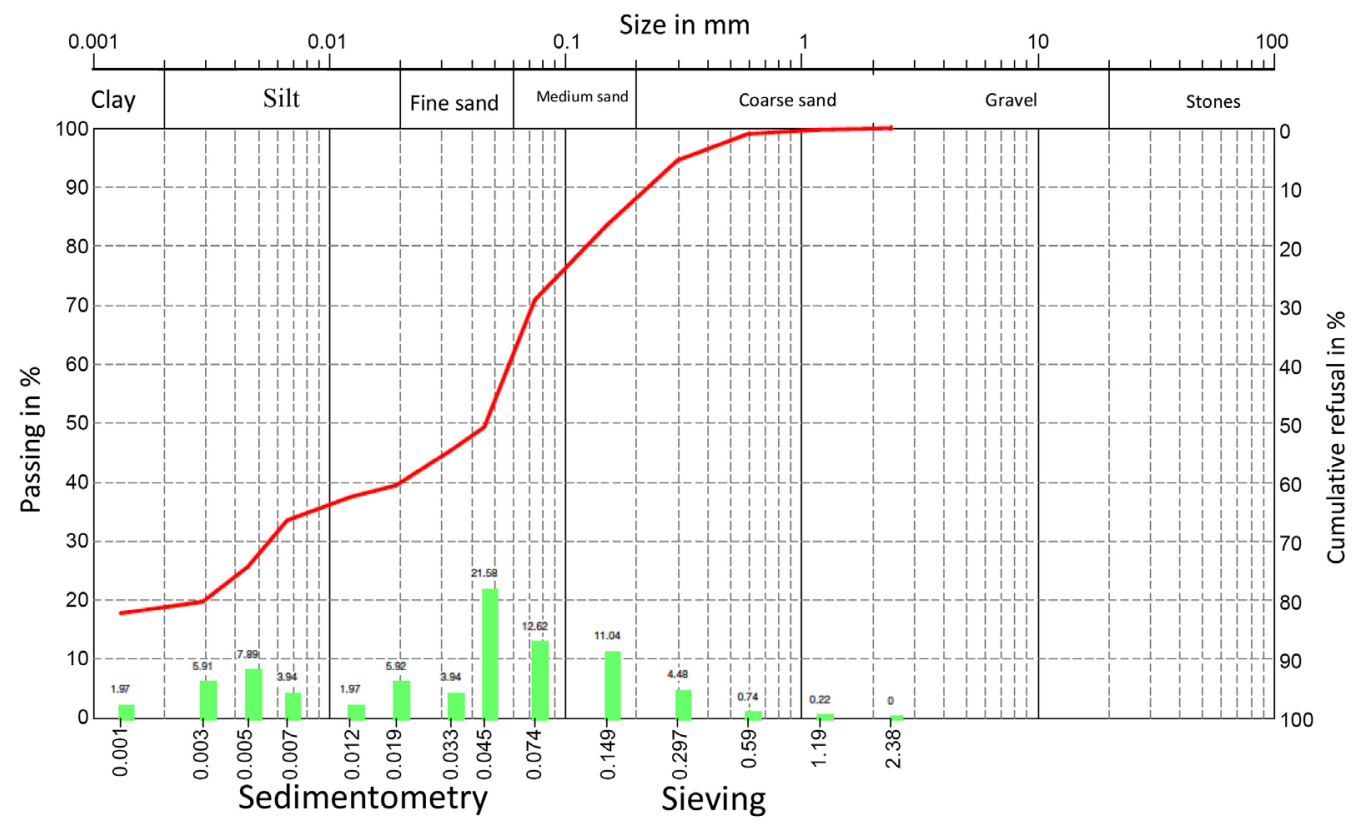

(b)

Figure 3. Particle size distribution of the soil. (a) Adina 1 and (b) Adina 2. 


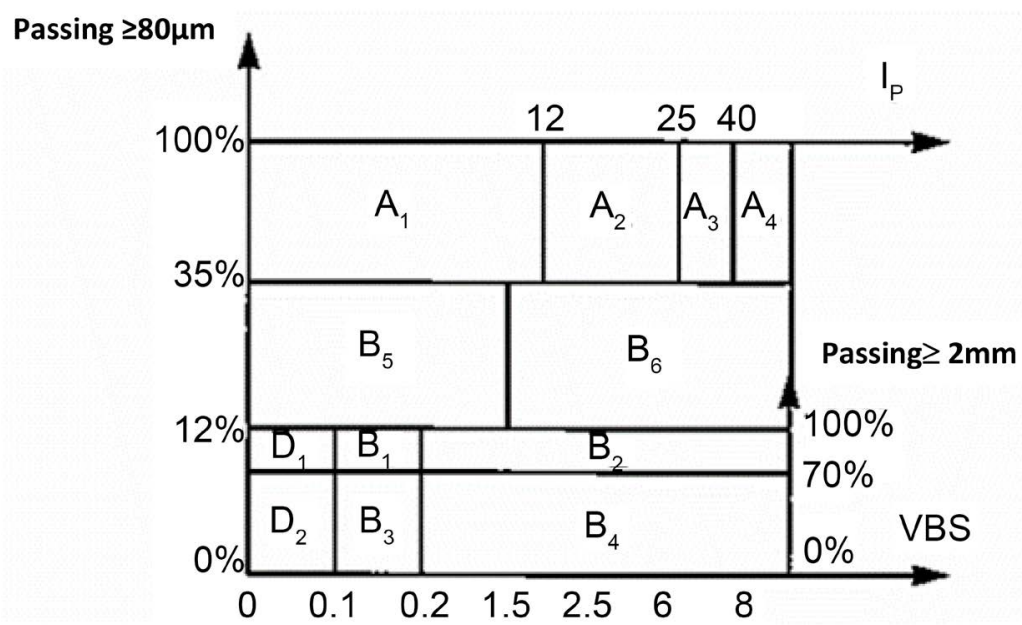

Figure 4. Material classification chart according to Casagrande.

structures built of clay or based on swelling materials. To get an idea of the soil swelling and shrinkage, it is necessary to calculate the activity coefficient $C_{a}$ [20] which is the ratio between $I_{p}$ and the percentage of grains below $2 \mu \mathrm{m}$ :

$$
C_{a}=\frac{I_{p}}{\% \text { of clay }}
$$

The soils activity coefficients $\left(C_{a}\right)$ are 0.685 and 0.479 respectively for Adina 1 and Adina 2. With these $C_{a}$ values $<0.75$ then it can be concluded that these soils do not have a high susceptibility to swelling and shrinking compare with the result of Paulus (2015) [20].

\subsection{Compressed Stabilized Earth Block Specimen Preparation}

The manufacture of CSEB is based on the principle of compacting clay-sand matrices optimized according to the water content and grain size of the mixture [21]. It is done in 3 steps: preparation of the soil material from, which the samples have been extracted by surface excavation, compression of the mixture introduced into a $16 \times 4 \times 4 \mathrm{~cm}$ mould, and hardening. Referring to previous studies conducted with straw as stabilizers for clay bricks, Djohore Ange Christine et al. (2018) [22] indicate that the presence of these straw will prevent shrinkage and swelling responsible for cracks, thus improving physical properties and mechanical resistances. In the preparation of the soil, it must be given an appropriate compressive load to obtain the best result and after the mixture has been placed in the mould [2].

In order to make blocks, the static compaction was applied on the mixtures, according to C.D.E (Centre for Development of Enterprise) method as [16]. To do this, a constant load of 1.5 tonnes is applied to the mixture to optimize the use properties of the CSEB based on the Proctor test standard result. Compressing the mixture was necessary to obtain the preferred property and limiting production costs and extend the use of stabilized bricks to all types of brick classes [23]. Table 2 summarizes the types of CSEB formulated mixtures: 
Table 2. Types of CSEB formulated.

\begin{tabular}{|c|c|c|c|}
\hline Designation & Description of components & Designation & Description of components \\
\hline A1-NS & Adina 1 without stabilizer & A2-NS & Adina 2 without stabilizer \\
\hline $\mathrm{A} 1-\mathrm{CV}$ & Adina $1+1.5 \%$ of lime & $\mathrm{A} 2-\mathrm{CV}$ & Adina $2+1.5 \%$ of lime \\
\hline A1-3FF & Adina $1+3 \%$ of fonio straw & A2-3FF & Adina $2+3 \%$ of fonio straw \\
\hline $\mathrm{A} 1-\mathrm{CV}-3 \mathrm{FF}$ & $\begin{array}{c}\text { Adina } 1+1.5 \% \text { of lime }+3 \% \text { of } \\
\text { fonio straw }\end{array}$ & $\mathrm{A} 2-\mathrm{CV}-3 \mathrm{FF}$ & $\begin{array}{c}\text { Adina } 2+1.5 \% \text { of lime }+3 \% \text { of } \\
\text { fonio straw }\end{array}$ \\
\hline A1-3RL & $\begin{array}{c}\text { Adina } 1+3 \% \text { of shea butter } \\
\text { residue from Lena }\end{array}$ & $\mathrm{A} 2-3 \mathrm{RD}$ & $\begin{array}{c}\text { Adina } 2+3 \% \text { of shea butter } \\
\text { residue from Dedougou }\end{array}$ \\
\hline A1-5RL & $\begin{array}{c}\text { Adina } 1+5 \% \text { of shea butter } \\
\text { residue from Lena }\end{array}$ & A2-5RD & $\begin{array}{c}\text { Adina } 2+5 \% \text { of shea butter } \\
\text { residue from Dedougou }\end{array}$ \\
\hline A1-10RL & $\begin{array}{c}\text { Adina } 1+10 \% \text { of shea butter } \\
\text { residue from Lena }\end{array}$ & $\mathrm{A} 2-10 \mathrm{RD}$ & $\begin{array}{c}\text { Adina } 2+10 \% \text { of shea butter } \\
\text { residue from Dedougou }\end{array}$ \\
\hline
\end{tabular}

In this study, the CSEB specimen was then removed from the mould and were stored and submitted to 7 days and 28 days curing time (Figure 5) under laboratory conditions at a temperature of $21^{\circ} \mathrm{C} \pm 1{ }^{\circ} \mathrm{C}$ and a relative humidity of $60 \%$ $\pm 10 \%$ until testing as did by Izemmourena \& Guettala (2014) [24]. These conditions allow us to avoid accelerated water loss and cracks. Because during their lifetime, earth walls must face significant variations in indoor and outdoor relative humidity, which induces variations and gradients in their water content [25].

\subsection{Test Constructed for CSEB Characterization}

A soil could be considered suitable for stabilization if its compressive strength exceeds $2 \mathrm{MPa}$ [3] Nevertheless, the compressive strength is dependent on the brick dimensions [26] [27]. To do this, we carried out tests to proceed to thermophysical and mechanical characterization of the CSEB, as synthesized in the diagram in Figure 1. The Blocks tests performed in this study were compressive strength, flexural strength, thermal tests (thermal conductivity, specific heat and thermal diffusivity) and durability tests (capillary coefficient, accessible porosity, microdrip absorption).

The mechanical 3-point bending strength was measured on the $4 \times 4 \times 16 \mathrm{~cm}^{3}$ specimens, the principle of which is shown in the figure below and presented in Figure 6 proposed by [28]. The compressive strength is obtained on the two half blocks resulting from the bending failure, in accordance to CRATerre's recommendations for tests on solid blocks and applied by [29] and [8]. The operating mode is as follows:

- superimpose the two $1 / 2$ blocks between the press plates;

- apply continuously and linearly increasing rate the load until the sample is completely ruptured.

Thus, the compressive strength $\left(R_{C}\right)$ of the blocks is obtained by the formula below: 


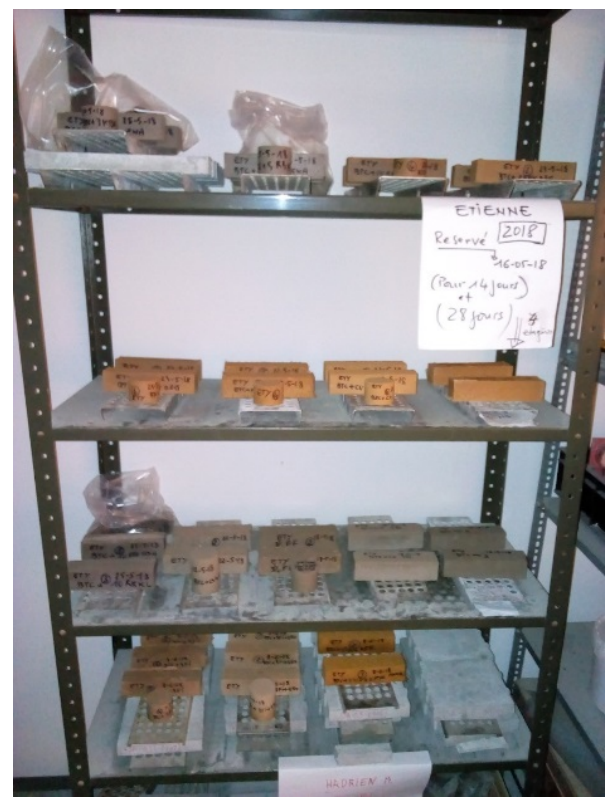

Figure 5. CSEB during the cure period.

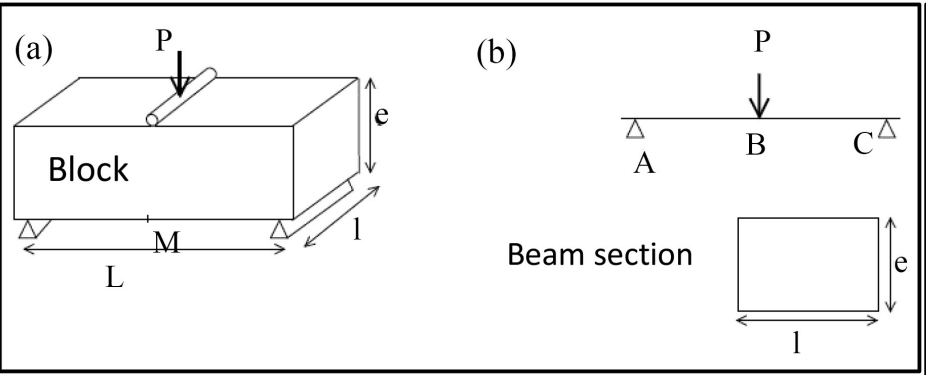

(c)

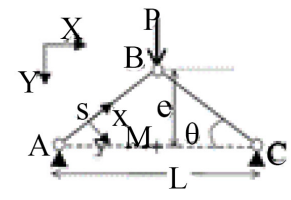

Beam

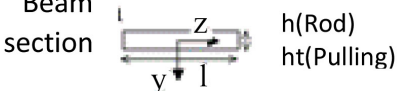

Figure 6. (a) Flexure strength principle; (b) Usual modeling; (c) Modeling by rods and pulling.

$$
R_{C}(\text { en } \mathrm{MPa})=\frac{10 \times F}{S}
$$

where, $F$ and $S$, are respectively the maximum applied load $(k N)$ and the application surface $\left(\mathrm{cm}^{2}\right)$.

The thermal conductivity $\mathrm{k}(\mathrm{W} / \mathrm{m} \cdot \mathrm{K})$ was measured using Liège university geotechnology laboratory test device (Figure 7) and based on the heating wire method using the TP 02 probe, in accordance with ASTM D 5334-00, D 5930-97 and IEEE 442-1981 standards. The Standard Test Methods" specifies the use of non-stable probes (NSSP) which after a short transition period, the temperature increase, $\Delta T$, depends only on the heating power, $\mathrm{Q}$, and the average thermal conductivity, $\lambda$.

$$
\Delta T=(Q / 4 \sqcap \lambda)(\ln t+B)
$$

where: $\Delta T$, in ${ }^{\circ} \mathrm{K}, Q$ in $\frac{w}{m}, \lambda$ in $\frac{w}{m \cdot K}, t$ in $s$ and $B$, a constant.

In the test principle, a groove was made in the CSEB where the heating needle was introduced before heating the sample. 


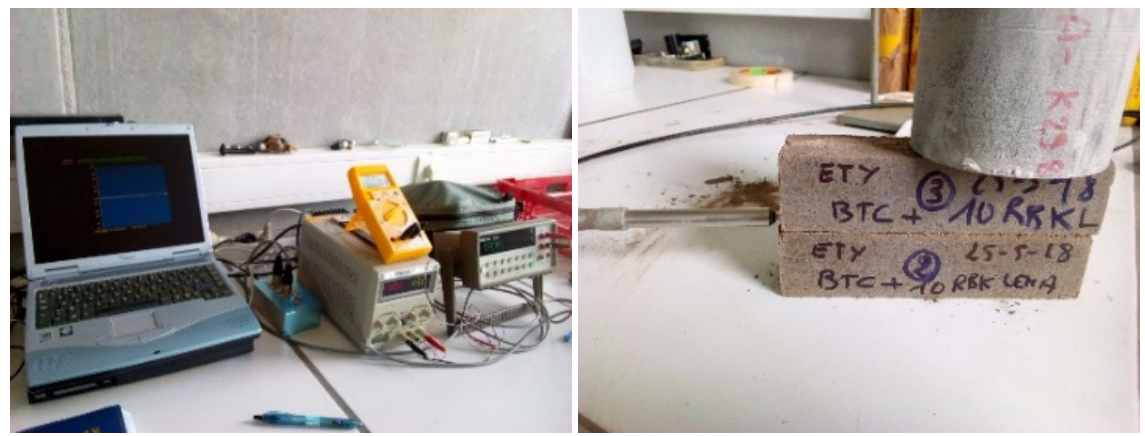

Figure 7. Measurement of thermal conductivity of CSEB after 14 and 28-days cure.

The specific heat is measured on samples of brick is previously heated and introduced into an isotherm (or calorimeter in the general case) containing a quantity of cold water. Thermocouples from CAMPBELL Scientific are introduced into the material and into the water in order to follow the temperature evolution [30]. The heat balance between the initial instant $t=0$ (introduction of the solid into the calorimeter) and the instant $t$ when the maximum temperature in the isometer is reached is written by the equation:

$$
m_{s} C_{P m}\left(T_{i-m}-T_{f}\right)=\left(m_{\text {eau }} C_{\text {eau }}\left(T_{f}-T_{\text {i-еаu }}\right)\right)+\int_{0}^{t} U S\left(T_{c}-T_{a}\right) \mathrm{d} t
$$

In an isothermal enclosure, CSEB specific heat $\left(C_{P . C S E B}\right.$ en $\left.\mathrm{J} / \mathrm{kg} .{ }^{\circ} \mathrm{C}\right)$ expression becomes:

$$
C_{P . \text { CSEB }}=\frac{m_{\text {eau }} C_{\text {eau }}\left(T_{f}-T_{i-\text { eau }}\right)}{m_{s} C_{P s}\left(T_{i-m}-T_{f}\right)}
$$

From $\lambda$ and $C_{P}$ CSEB diffusivity (a) is deducted by following formula:

$$
a\left(m^{2} / s\right)=\frac{\lambda}{\rho c}
$$

Finally, we were interested in studying the durability of CSEB, since the problem with the traditional use of soil material is its durability [24]. Indeed, as V. Sharma et al. (2016) [31] states, low durability and compressive strength of adobe blocks leads to frequent maintenance problem associated with rural house wall construction. Due to the small quantity of materials available during the test campaign that was carried out at the Building Materials Laboratory of the University of Liège (Belgium), CSEB durability was studied on the pieces of blocks resulting from the mechanical tests. These fragments are cut to regular cubic dimensions $4 \times 4 \times 4 \mathrm{~cm}$ and subjected to different types of tests. Base on ASTM D 55957 standard described by [32], the CSEB durability analysis will focus on the water-repellent behaviour of samples by microdrip absorption tests (Figure 8), and measurement of the sponge contact capillary coefficient (and accessible porosity. In general, it is the dominant fraction of a soil that characterizes its fundamental properties and dictates its behavior [33].

According to Vissac et al. (2017) [14] the measurement of the capillary coefficient can be evaluated by the sponge contact method (Figure 9). The previously 


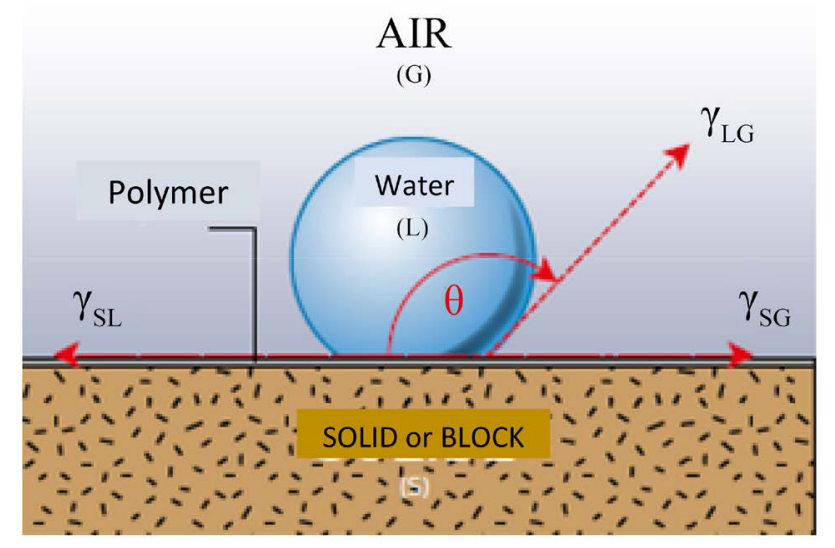

Figure 8. Contact angle measurement on a water-repellent surface [32].

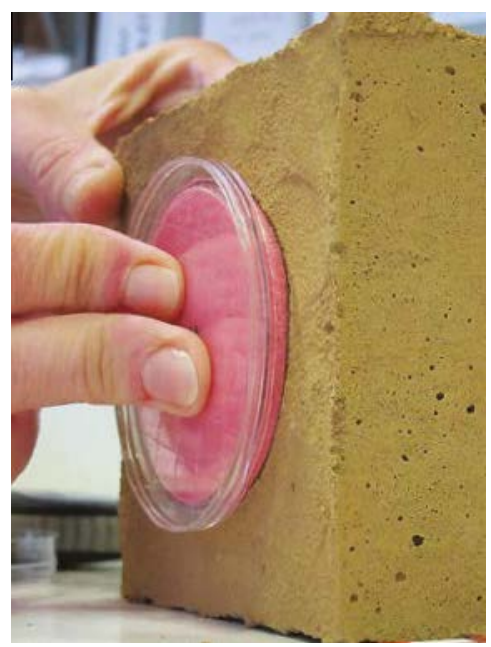

Figure 9. Sponge contact test principle [14].

wet and weighed sponge is applied to the earth surface with constant pressure and for 10 minutes. The sponge is weighed again and the amount of water absorbed by the earth surface is deducted from both weighs.

\section{Result}

\subsection{Assessment of Soils Materials Adaptability}

Two types of clay materials have been characterized and the results of the physical and mineralogical analyses guide us on their adaptability to construction, in comparison with the recommended grain size range, according to the requirements of CRATerre [25] [34], the standards (NF, ASTM) and the results of previous studies [8]-[35]. The main physical properties of the materials studied are summarized in Table 3.

The results of the mineralogical studies by the XRD and geotechnical studies carried out on the two soils shown values fairly close and they are composed of main minerals such as Quartz (75 wt\% and $71 \mathrm{wt} \%$ ), Kaolinite (13 wt\% and 15 $\mathrm{wt} \%$ ), and the K-Feldsp (8 wt\% and $5 \mathrm{wt} \%$ ). Compared to previous result [36] it 
Table 3. Synthesis of soils physical's properties.

\begin{tabular}{ccccccc}
\hline \multicolumn{3}{c}{ Particle size distribution } & \multicolumn{3}{c}{ Plasticity } \\
\hline & & Adina 1 & Adina 2 & Parameters & Adina 1 & Adina 2 \\
\hline Gravel & $>2 \mathrm{~mm}$ & $1 \%$ & $1 \%$ & $W_{L}(\%)$ & 22.64 & 25.03 \\
Sand & $0.063-2 \mathrm{~mm}$ & $72 \%$ & $59 \%$ & $W_{P}(\%)$ & 11.68 & 16.02 \\
Silt & $0.002-0.063$ & $11 \%$ & $21.2 \%$ & $I_{P}(\%)$ & 10.96 & 9.02 \\
Clay & $<0.002 \mathrm{~mm}$ & $16.0 \%$ & $18.8 \%$ & VBS & 3 & 3 \\
Specific grain weight $\left(\mathrm{kN} / \mathrm{m}^{3}\right)$ & 2.66 & 2.73 & & & \\
Apparent dry density $\left(\mathrm{g} / \mathrm{cm}^{3}\right)$ & 1.87 & 1.91 & & & \\
\multicolumn{2}{c}{$\boldsymbol{\omega}_{\text {opt }}(\%)$} & 11.6 & 10.3 & & & \\
\hline
\end{tabular}

is a sandy-silty clay of medium plasticity containing no swelling minerals and the particle are mainly Sand (72 wt\% and $59 \mathrm{wt} \%$ ), Silt (11 wt\% and $21.2 \mathrm{wt} \%$ ) and clay ( $16.0 \mathrm{wt} \%$ and $18.8 \mathrm{wt} \%)$. The low smectite rate, the methylene blue value (VBS $=3)$ and the activity coefficient $\left(C_{a}<0.75\right)$ results indicate that these materials do not contain enough swelling clay minerals and susceptibility shrinkage and they are thus suitable for the development of earth material for habitats.

These different results allow us to conclude that the earth materials Adina 1 and Adina 2, are suitable as building materials. Thus, they will be used as a matrix of CSEB. In addition, to further support these two materials adaptability study we will carry out durability tests of the formulated CSEB.

\subsection{Physical and Mechanical Characteristics of CSEB}

\subsubsection{Physical Properties}

A more detailed analysis was carried out to verify whether the density of the material influences its mechanical strength. Figure 10 gives the average dry density values obtained by type of CSEB according to the earth material, the type of stabilization and under optimum Proctor conditions.

In Figure 10, the types of blocks without stabilizer (A1NS and A2NS) have the highest dry density values. This is justified because they have not been incorporated with organic materials. Also, the Figure indicates that the dry density decreases with the percentage of incorporation of shea butter residues. In addition, the blocks stabilized with the shea butter residue have higher dry density values $\left(1.87 \mathrm{~g} / \mathrm{cm}^{3}\right)$ than those stabilized with fonio straw with or without quicklime, for a comparable substitution rate. The following graphs present the results of bending strength $\left(R_{f}\right)$ and compressive strength $\left(R_{c}\right)$ as a function of the dry density of the CSEB.

\subsubsection{CSEB Flexural Strength}

The value of the 3-point bending was carried out on all types of CSEB and the result is presented in Figure 11. It shows the effect of fonio straw on CSEB flexural strength. 


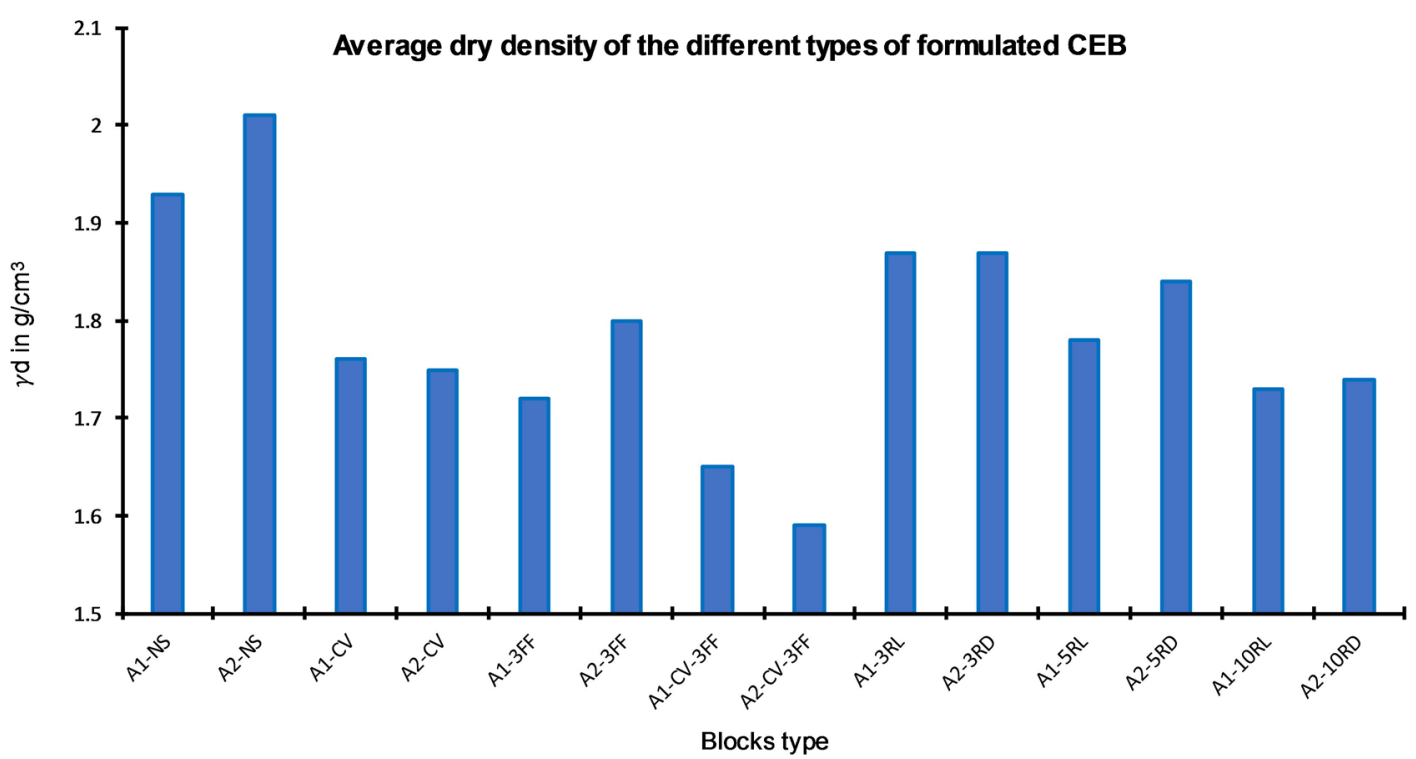

Figure 10. Synthesis of CSEB average dry density.

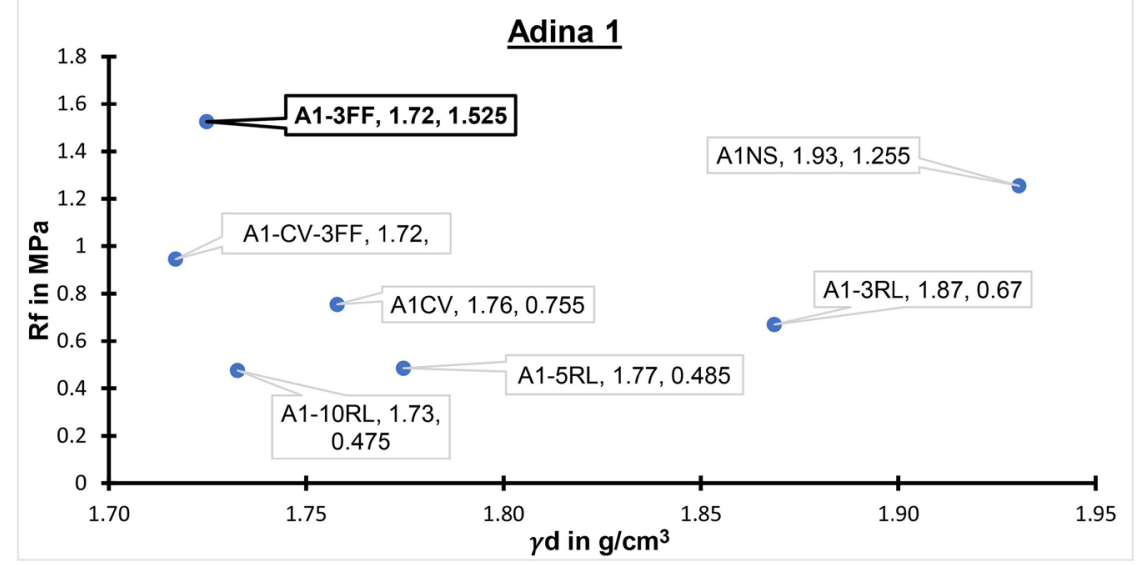

(a)

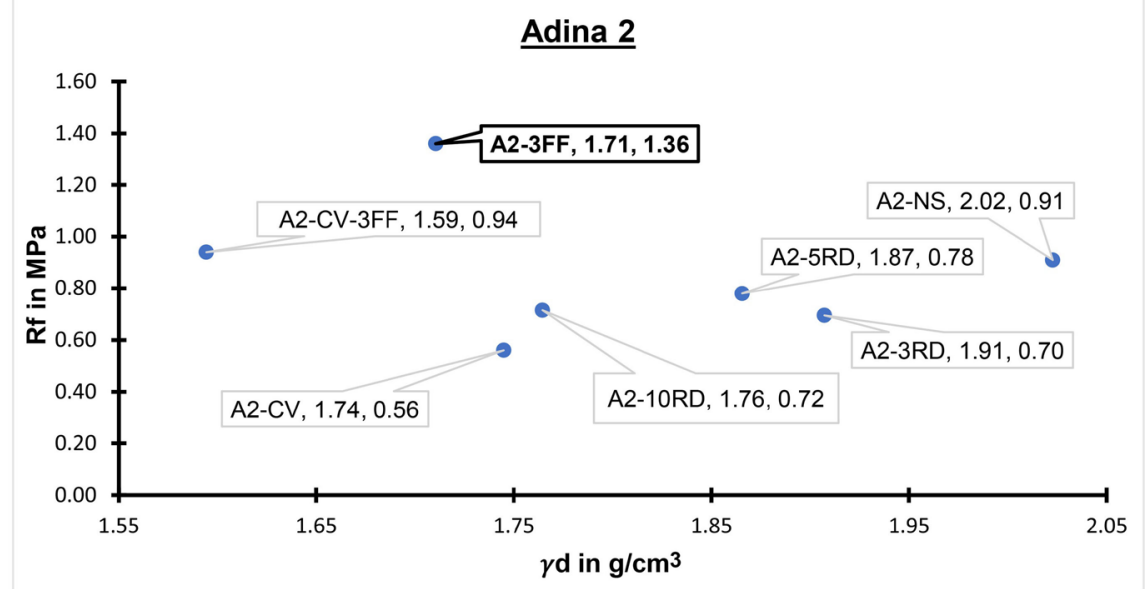

(b)

Figure 11. CSEB flexural strength according to their dry density at 28 days old. (a) Adina 1 and (b) Adina 2. 
The results of the tests carried out on thirteen (13) CSEB show that after 14 days of age, the blocks have an average 3-point bending strength $\left(R_{f}\right)$ between 0.4 and $1.5 \mathrm{MPa}$ for Adina 1 and 0.6 and $1.6 \mathrm{MPa}$ for Adina 2 . At 28 days the $R_{f}$ values range from 0.5 to $1.3 \mathrm{MPa}$ for Adina 1 and 0.6 and 1.4 $\mathrm{MPa}$ for Adina 2, representing an average increase of 7.4\% and 3.4\%, respectively, for Adina 1 and Adina 2. Figure 4 shows that CSEB high density value does not necessarily imply a high three-point bending strength. For proof, the highest values of $\mathrm{Rf}(1.525$ $\mathrm{MPa}$ and $1.36 \mathrm{MPa}$ ) are obtained with specimens stabilized with $3 \%$ fonio straw (A1-3FF and A2-3FF) and density respectively 1.72 and 1.71. That result is an agreement with [1]. The lowest value is obtained on blocks with double stabilization quicklime/fonio straw and this can be explained by the slow hardening due to the presence of lime and the optimal low water content used. Note that this category of Blocks crumbles to the touch.

Moreover, quicklime does not improve the CSEB bending strength and shea butter residue incorporation in CSEB does not significantly modify their bending strength.

\subsubsection{CSEB Compressive Strength}

The relationship between compressive strength $\left(R_{c}\right)$ and dry density of the material is more pronounced than in the bending strength analysis as indicated in Figure 11. In general, compressive strength tends to increase with the dry density of the material, but CSEB high density value does not necessarily imply a high compressive strength (Figure 12).

The average compressive strength $\left(R_{c}\right)$ values obtained are between 1.4 and 5 $\mathrm{MPa}$ for Adina 1 and between 1.2 and $3 \mathrm{MPa}$ for Adina 2 to 14 days old. At 28-days old, the CSEB $R_{c}$ values are ranging from 1.2 to $3.8 \mathrm{MPa}$ for Adina 1 and from 1.1 to 3.8 MPa for Adina 2. The addition of more shea butter results in a decrease in compressive strength. Similarly, CSEB specimens incorporating quicklime have lower compressive strength values than comparable specimens without the addition of quicklime. The highest values of CSEB $R_{c}$ are obtained on specimens incorporating fonio straw and on those formulated only by earth material. However, for the new composite materials studies, values of $R_{c}>2$ $\mathrm{MPa}$ (minimum values recommended by CRATerre for CSEB) are observed for CEB incorporating 3\% fonio straw, $3 \%$ and $5 \%$ shea butter residue.

\subsection{CSEB Thermal Performance Analysis}

\subsubsection{Thermal Conductivity}

Thermal conductivity is the property of materials to transmit heat by conduction. The lower the thermal conductivity of material, the greater is its insulation [16]. The graphs in Figure 13(a) and Figure 13(b) show the evolution different types CSBE thermal conductivity average values at 14 and 28 days of old of cure. Generally speaking, $\lambda$ evolves according to CSEB density, as already observed by J. Laurent (2010) [37]. However, thermal conductivity values are significantly lower for CSEB incorporating organic and biopolymer materials (shea butter residue 


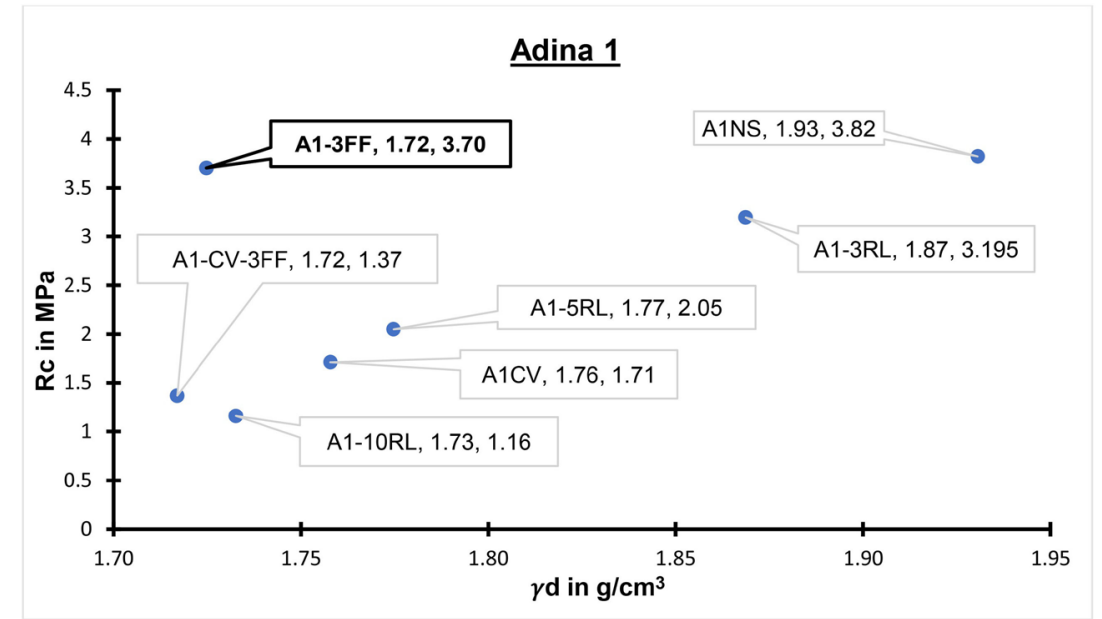

(a)

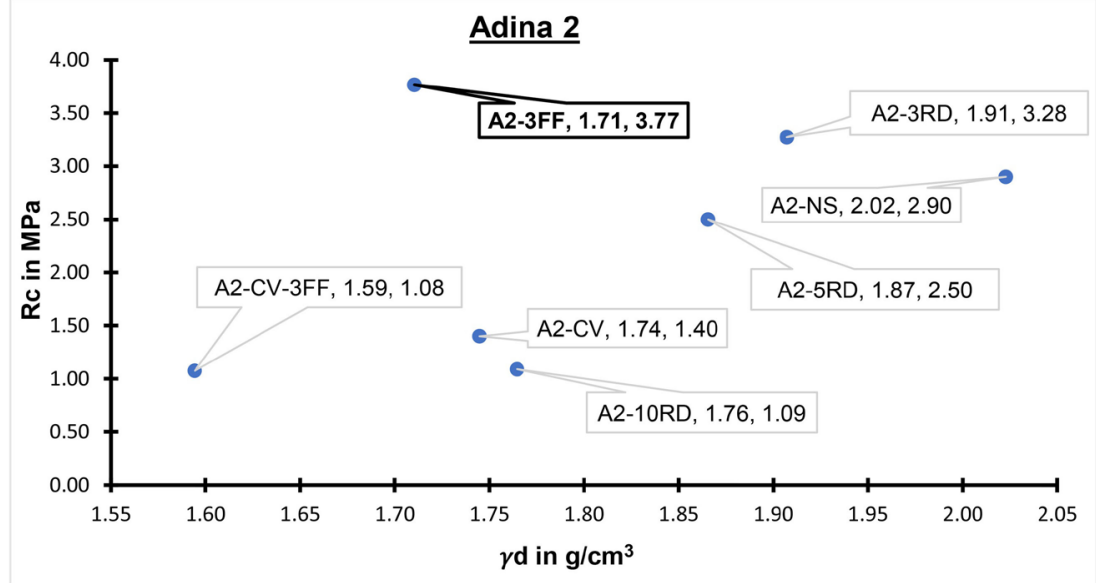

(b)

Figure 12. CSEB Compressive strength $\left(R_{c}\right)$ according to dry density at 28 days. (a) Adina 1 and (b) Adina 2.

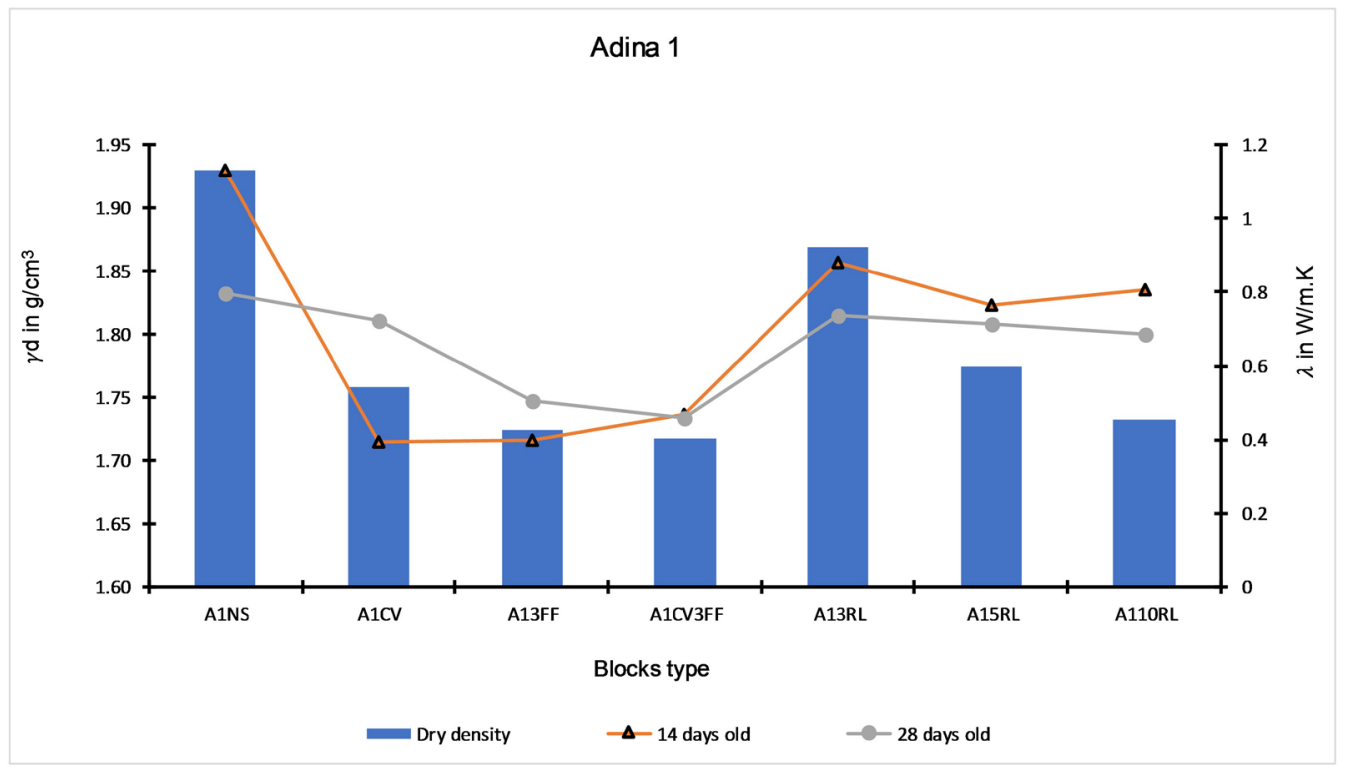

(a) 


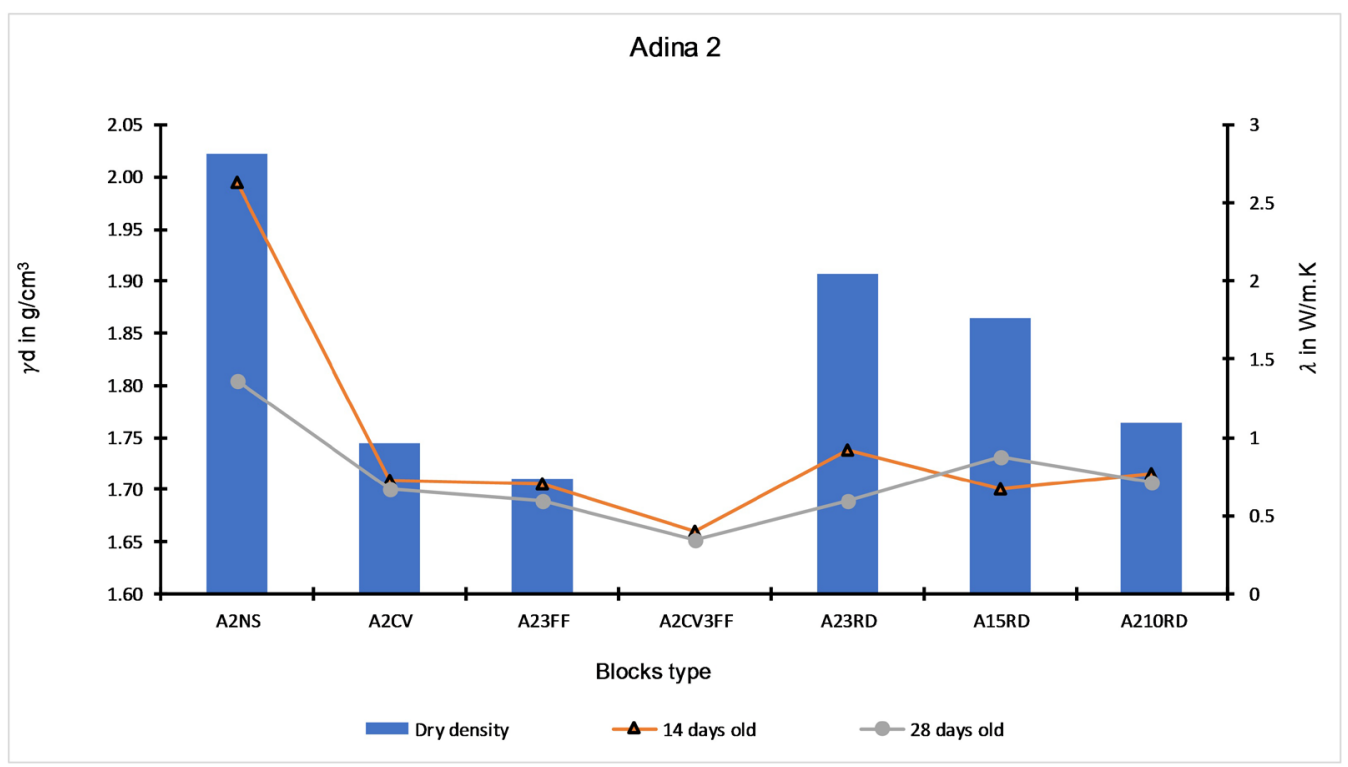

(b)

Figure 13. CSEB thermal conductivity after 14- and 28-days cure. (a) Adina 1 and (b) Adina 2.

and fonio straw), and with quicklime. Therefore, to conclude, the stabilizers used contribute to improving thermal conductivity and it increases as a function of stabilizers contents already shown by M. Saidi et al. (2018) [10], and Imbga et al. (2018) [38]. The lowest thermal conductivity values $(\lambda=0.549 \mathrm{~W} / \mathrm{m})$ were measured in CSEB incorporating 3\% fonio straw.

\subsubsection{Specific Heat Mass and Thermal Diffusivity}

The measurement of specific heat by mass $\left(C_{p}\right)$ is carried out by a system set up in the Building Materials Laboratory of the University of Liège (Belgium). It is composed of an isotherm and thermocouples from CAMPBELL Scientific. It is determined by applying the following equation:

The results of the specific heat mass and thermal diffusivity obtained for each type of CSEB studied are summarized in Table 4.

The $\mathrm{Cp}$ values are between 1050 and $1967 \mathrm{~J} / \mathrm{kg} \cdot{ }^{\circ} \mathrm{C}$ for Adina 1 and between 1253 and $1916 \mathrm{~J} / \mathrm{kg} \cdot{ }^{\circ} \mathrm{C}$ for Adina 2, which are close to other values such as the average value of $1.5 \mathrm{~kJ} / \mathrm{kg} .{ }^{\circ} \mathrm{C}$ found by E. Ouedraogo et al. (2015) [9] on other types of CSEB studied and the value of $1700 \mathrm{j} / \mathrm{kg} .{ }^{\circ} \mathrm{C}$ given by CRATerre. The measurements of $C_{p}$ and $\lambda$ make it possible to calculate the thermal diffusivity (a) which constitutes one of building material thermal behavior determining factors. It intervenes in the building thermal comfort calculation. Thermal diffusivity is generally lower when CSEB are manufactured with vegetable by-products (shea butter residue and fonio straw). The lowest values are reached for specimens incorporating fonio straw. However, it should be noted that CSEB thermal characteristics also depend on soil material density and grains distribution.

\subsection{Physical and Durability Analysis of CSEB}

One of the major difficulties in the use of earth material in construction is the 
Table 4. CSEB thermal diffusivity after 28 days old.

\begin{tabular}{|c|c|c|c|c|c|c|c|}
\hline Adina 1 & & & & & & & \\
\hline Type of CSEB & A1NS & $\mathrm{A} 1 \mathrm{CV}$ & A13FF & A1CV3FF & A13RL & A15RL & A110RL \\
\hline$C_{p}($ mean $)\left(\right.$ in $\left.\mathrm{J} / \mathrm{kg} \cdot{ }^{\circ} \mathrm{C}\right)$ & 1448.2 & 1050.2 & 1967 & 2149.6 & 1578.5 & 1489.8 & 1373 \\
\hline $\boldsymbol{\rho}\left(\mathrm{Kg} / \mathrm{m}^{3}\right)$ & 1959 & 1792 & 1761 & 1574 & 1892.5 & 1792.5 & 1733 \\
\hline$\lambda($ in $\mathrm{w} / \mathrm{m} \cdot \mathrm{K})$ & 0.795 & 0.724 & 0.504 & 0.46 & 0.7375 & 0.716 & 0.688 \\
\hline $\begin{array}{l}\text { Thermal diffusivity (a) } \\
\text { (in } 10^{-7} \mathrm{~m}^{2} / \mathrm{s} \text { ) }\end{array}$ & 2.80 & 3.85 & 1.45 & 1.36 & 2.47 & 2.68 & 2.89 \\
\hline \multicolumn{8}{|l|}{ Adina 2} \\
\hline Type of CSEB & A2NS & $\mathrm{A} 2 \mathrm{CV}$ & A23FF & A2CV3FF & A23RD & A25RD & A210RD \\
\hline$C_{p}($ mean $)\left(\mathrm{in} / \mathrm{kg}^{\circ} \mathrm{C}\right)$ & 1556.8 & 1253.7 & 1775.3 & 1916.9 & 1552.7 & 1341.7 & 1428.1 \\
\hline $\boldsymbol{\rho}\left(\mathrm{Kg} / \mathrm{m}^{3}\right)$ & 2052 & 1721 & 1779 & 1614.5 & 1919.5 & 1912 & 1959.9 \\
\hline$\lambda($ in $w / m \cdot K)$ & 1.361 & 0.6705 & 0.5945 & 0.342 & 0.5975 & 0.88 & 0.7095 \\
\hline $\begin{array}{l}\text { Thermal Diffusivity (a) } \\
\text { (in } 10^{-7} \mathrm{~m}^{2} / \mathrm{s} \text { ) }\end{array}$ & 4.26 & 3.107 & 1.882 & 1.105 & 2.005 & 3.43 & 2.535 \\
\hline
\end{tabular}

constraint related to durability in the face of rainy weather. In order to improve its durability, the material must be the least permeable to water. This aspect is analyzed through three types of tests: the measurement of the contact angle, the capillary coefficient by sponge contact and the accessible porosity. These tests are initiated to imitate the rainy and dry seasons alternation in the study area as [31] may lead to alternating wetting and drying for the CSEB.

\subsubsection{Contact Angle}

A drop of water is placed on the specimen facet with a syringe and the contact angle of the water drop is then measured. When $\alpha \geq 90^{\circ}$ it is said that the liquid does not wet the brick.

Figure 14 shows that the contact angle increases with the percent of shea butter residue in the CSEB, regardless of the soil material studied. This is logical, as shea butter is used as a biopolymer in the surface treatment of earthen constructions [14].

\subsubsection{Coefficient of Capillarity by Sponge Contact}

The sponge contact test is a reliable, accessible and field applicable test with little equipment, recommended by CRATerre [14]. Contact is between the wet sponge and the material is maintained for 90 seconds before measuring capillary absorption. The results are presented in Figure 15(a) and Figure 15(b).

Analysis of the graphs shows that capillary absorption is lower for CSEB by shea butter residues for both types of soil materials.

\subsubsection{Accessible Porosity of CEB Stabilized with Shea Butter Residue} The accessible porosity measurements are made on CSEB incorporated by shea butter residue (RBK). This choice is due to the fact that this stabilizer is a biopolymer material that has shown the most favourable characteristics in terms of durability following measurements of the capillary coefficient. 


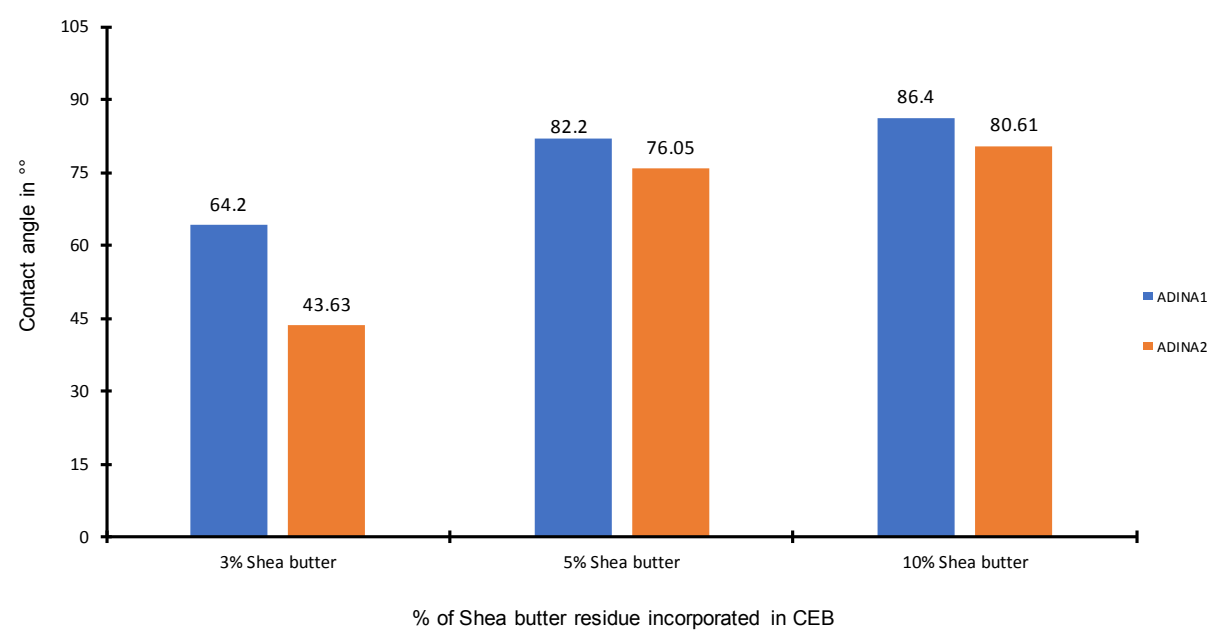

Figure 14. Contact angle of CSEB with Shea butter residue.

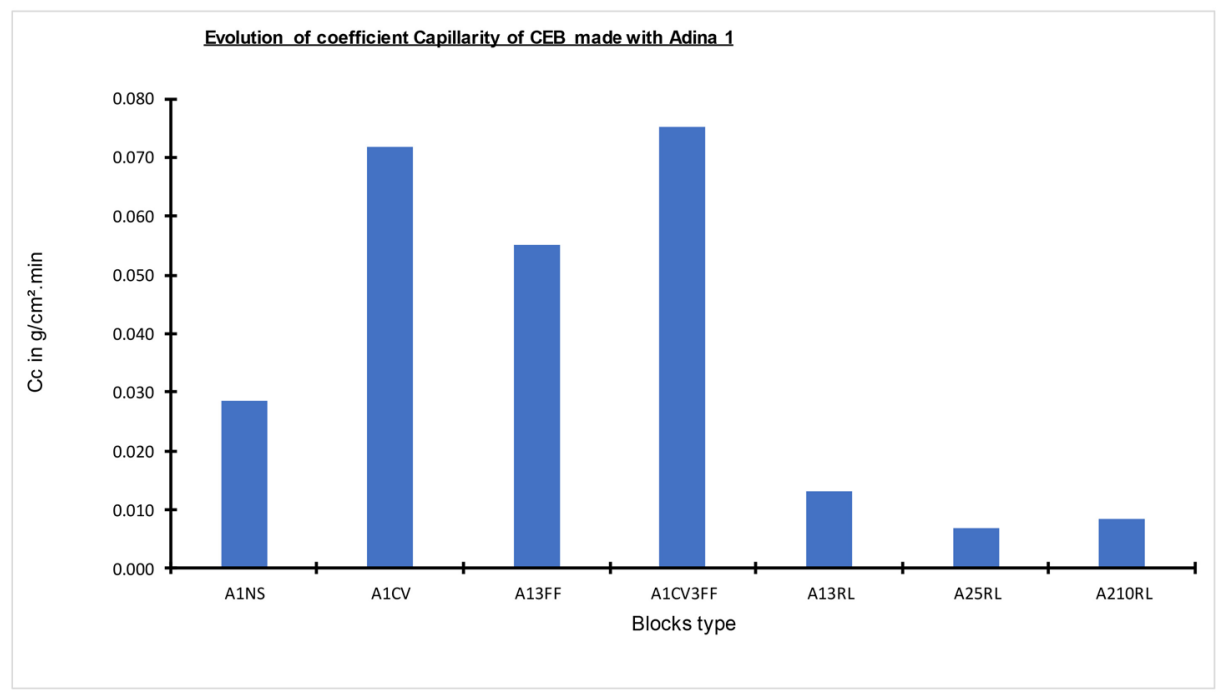

(a)

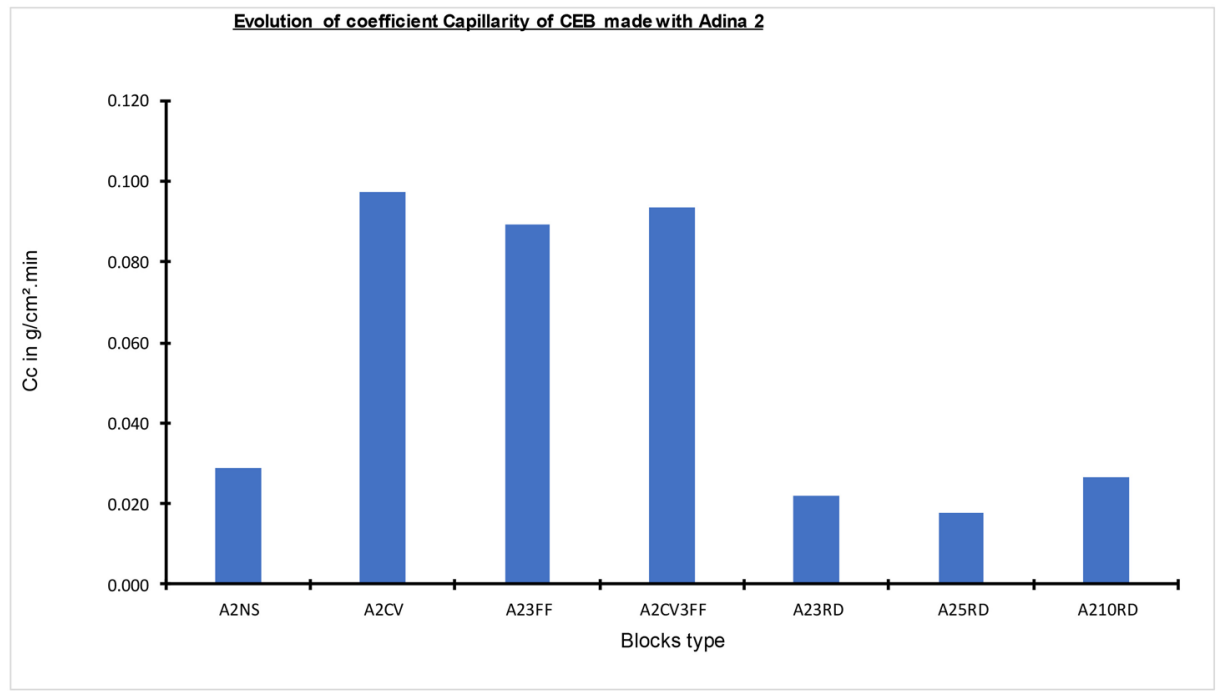

(b)

Figure 15. Coefficient of capillarity of CSEB. (a) Adina 1 and (b) Adina 2. 
In Figure 16, the curve shows a similar trend of decreasing accessible porosity for CSEB incorporating shea butter residue from Lena (RL) and Dedougou (RD) (Burkina Faso).

\section{Discussion}

\subsection{Summary of Main Findings}

The mechanical characterization of CSEB formulated in this study gave 3-point bending and compressive strength according to CSEB type for both of two cure times. It can be seen that the stabilizers used (fonio straw, shea butter residue) influence differently the CSEB mechanical behaviour and it can be noted that:

- the presence of $3 \%$ fonio straw leads to a decrease in dry density and a significant increase in $R_{f}$ and $R_{c}$ The mechanical resistances (both in bending and compressive strength) obtained on CSEB exceed those corresponding earth material block made without stabilizer. So the fonio straw incorporation increase CEB mechanical strength as kenaf straw study by [39] and Rice Husk Ash [36];

- the addition of quicklime (1.5\%) does not improve mechanical strength. This could be explained by the short cure time carried out in this study (maximum 28 days), whereas the effect of quicklime in CSEB is often observed from 45 days onwards;

- the contribution of shea butter residue is also noticeable on compressive strength and flexural strength. In general, the addition of RBK tends to reduce CSEB mechanical strength, whether in bending or compressive. The decrease in mechanical properties seems to be related to CSEB Shea butter residue content. This link is particularly observable with compressive strength measurements.

The analysis of the mechanical resistance therefore indicates that the most appropriate material for CSEB production is that made up of 3\% fonio straw. The mechanical strength obtained with Adina 1 soil material is slightly higher than that of Adina 2 soil material, which could be explained by a higher proportion

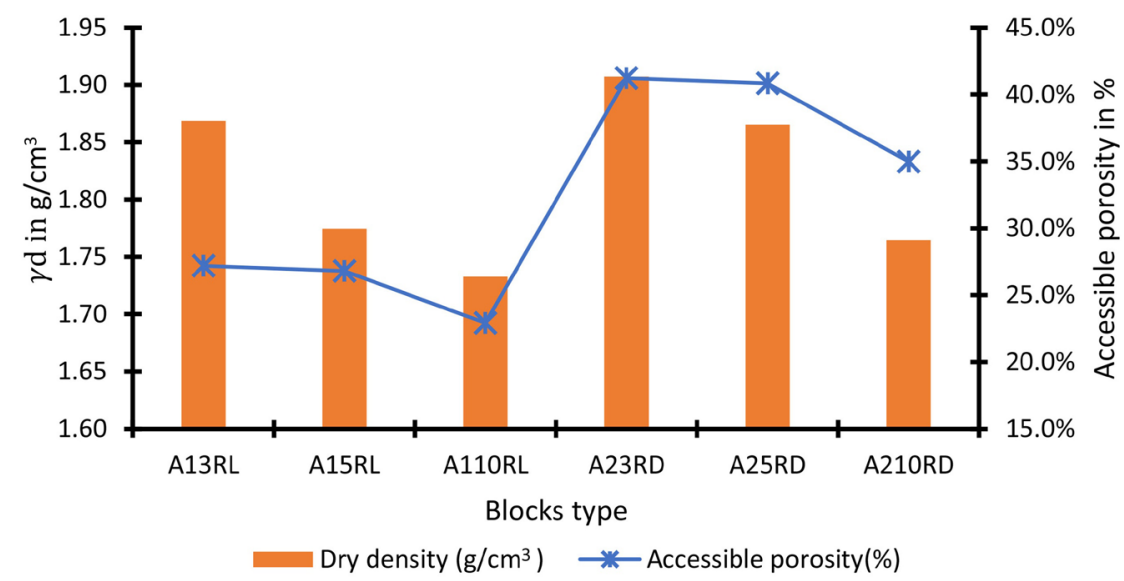

Figure 16. Evolution of accessible porosity of CSEB stabilized with shea butter residue. 
of coarser sand grains for Adina 1 than Adina 2. The evolution of the bending strength of blocks at 28 days of age is in the same trend as that at 14 days of age. It represents an average increase of $7.40 \%$ in flexion and $3.40 \%$ in compression for Adina 1 and 6.5\% in compression for Adina 2

The building materials thermal properties are an important factor in the choice of sustainable building materials. The characterization of thermal properties $\left(\lambda, C_{p}\right.$ and $\left.a\right)$ are functions, including CSEB density and the type of stabilizer used. In order to build dwellings using the CSEB studied, it is necessary to obtain the lowest thermal conductivity values in order to best insulate the interior of the building from the outside. This is even more important when housing is subject to a dry tropical climate. The most favourable results are obtained on CSEB specimen stabilized with 3\% fonio straw and 3\% - 10\% Shea butter residue, which have thermal conductivity and thermal diffusivity lowest values. Thus, we noticed on the specimens of CSEB stabilized with $3 \%$ of fonio straw, and $3 \%-10 \%$ of shea butter residue, that $\lambda$ decreased respectively by an average of $31.03 \%$ and $28.35 \%$.

The CSEB incorporated with shea butter residue show the most favourable durability properties. The two types of shea butter residue (grey and reddish) significantly reduce from $32.06 \%$ the accessible porosity and increase the CSEB water repellency. By the way, differences in these CSEB behaviour in contact with water were observed. The specimens stabilized with grey shea butter residue are more water-repellent than those stabilized with reddish one's and present also a lower percentage of accessible porosity. These differences can be explained in part by the difference in fat content, which is greater in grey shea butter and that reddish one has a drier appearance. This low-fat content leads to an increase in pores in the shea butter residue, making it less water-repellent.

The global CSEB characterization shows that some of them have acceptable use properties in construction. Those stabilized with $3 \%$ fonio straw show good mechanical characteristics but haven't optimal durability characteristics due to their unfavourable capillary properties. On the other hand, CSEB incorporating shea butter residue in the earth matrix shows good characteristics in terms of durability but less good mechanical characteristics. These results are in agreement with previous research works [7], [31] which state that addition of natural straw in soil improves the durability and strength of earth.

\subsection{Strength and Limitations}

We have developed two new composite construction materials that integrate natural secondary resources (agricultural and biopolymers by-products) with soil. Then, we determined their thermophysical and mechanical properties and compared to the minimum required by CRATerre's instructions, for single storey building envelope material. The main features of this study are:

- The good mechanical and thermal behaviour of CSEB reinforced by fonio straw (straw) offer make it possible as single storey construction materials;

- The innovated addition of shea butter residues as stabilizers enhances the 
heat transfer through the earthen materials and reduces CSEB water vapor permeability;

- The good durability of the CEB stabilized with shea butter residue is encouraging in their use for building walls water insulation;

- The valorization of fonio straw and shea butter residue in the value chain of these agricultural and forest resources, by incorporating in soil to formulate an eco-construction material.

This study is far from perfect, but the results obtained must be seen as a substantial constitution for research and the development of secondary resources in construction. In addition, the context was marked by various constraints such as:

- This study was conducted over a period of three and a half months, at the end of which results should be presented, which led to a time constraint and intensity of activities during the period.

- The small quantity of raw materials used, taking into account the conditions of the internship and it implies to reduce CSEB dimensions studied to $4 \times 4 \times 16$ $\mathrm{cm}$.

- The CSEB cure in laboratory conditions that are not identical to their real and natural conditions of use.

\subsection{Implications on Practice and Research}

This study highlights two complementary products that would be interesting to combine: CSEB incorporating fonio straw for walls and the use of earth material stabilized with residual shea butter for plaster or exterior wall coating. From these results, we notice that the grey shea butter residue from Lena shows the best water repellent qualities while the soil material Adina 1 presents the best physical and mechanical characteristics. They thus open up interesting prospects in terms of housing construction concrete applications based on CSEB produced by incorporating local secondary natural resources.

Fonio straw can be used at 3\% for CSEB and shea butter residue between 3\% $10 \%$ for composite coatings with the earth material. In terms of research prospects, we will be interested in:

- further characterization studies to determine the optimal level of RBK to achieve the water-repellent limit in the CSEB;

- further characterization studies with CSEB practice size;

- simulations of the thermal and energy behavior of a residential building built with these CSEB having mechanical characteristics that comply with the standard and interesting thermal properties and compared to other building materials used in Burkina Faso.

\section{Conclusions}

The analyses carried out on the different types of materials have enabled us to assess their suitability for use in housing construction. Study results show that 
the incorporation of $3 \%$ of fonio straw and $3 \%-10 \%$ of shea butter residues improves the mechanical, physical and thermal properties of the soil material. The compressed stabilized earth blocks (CSEB) obtained with these earth materials and the stabilizers from agricultural (fonio straw) and biopolymers' residues (shea butter residue) used in this study are local natural resources in Burkina Faso, depending on the type and percentage of stabilizers incorporated in the two earth materials studied to formulate CSEB, the physical, mechanical and thermal properties differ. We recommend, in practice, it is possible to combine the two types of stabilizers to form a new composite construction eco-material.

The study results indicate that it is possible to improve the soil properties in construction and we recommend the use of agricultural and forestry by-products such as fonio straw and shea butter residues. To do this, it is important to:

- cut the appropriate earth material, which can be a clayey sandy-silt or silty sandy-silt type;

- for the two type blocks, respect for each block the followings mixtures:

- A1-3FF or A2-3FF, use $435.5 \mathrm{~g}$ of soil + $13.056 \mathrm{~g}$ of fonio straw;

- A1-5RL or A2-5RB, use $435.5 \mathrm{~g}$ of soil + $21.8 \mathrm{~g}$ of shea butter residue;

- The mechanical mixture mean duration is five (05) minutes.

- Make a soil matrix and stabilizers dry mix before adding water up to the soil base water content; The water content depends on the soil type;

- Mix and obtain a homogeneous composite before introducing it into the mould;

- Apply the constant compressive load with reference to the Proctor test results;

- Do a block cure for 28 days before use for construction.

\section{Acknowledgements}

This study was conducted as part of the SERAMA program for Secondary Resources valuation for Sustainable Construction. This research was completely founded by the "Académie de Recherche et d'Enseignement Supérieur (ARES)" in Laboratory of Building Materials (LMC) and in Sustainable Building Design Lab Liège University. The author would like to acknowledge the valuable support of Geotechnology laboratory of the University of Liège and the Geology Laboratory of the University of Liège during experimentation. Also, we would like to acknowledge the support of the Institute of Environmental Engineering and Sustainable Development (IGEDD) of the University Joseph KI-ZERBO during the project submission.

\section{Conflicts of Interest}

The authors declare no conflicts of interest regarding the publication of this paper.

\section{References}

[1] Ouedraogo, M., et al. (2019) Physical, Thermal and Mechanical Properties of 
Adobes Stabilized with Fonio (Digitaria exilis) Straw. Journal of Building Engineering, 23, 250-258. https://doi.org/10.1016/j.jobe.2019.02.005

[2] Riza, F.V., Rahman, I.A., Mujahid, A. and Zaidi, A. (2010) A Brief Review of Compressed Stabilized Earth Brick (CSEB). CSSR 2010 International Conference on Science and Social Research, Kuala Lumpur, 5-7 December 2010, 999-1004.

[3] Pacheco-Torgal, F. and Jalali, S. (2012) Earth Construction: Lessons from the Past for Future Eco-Efficient Construction. Construction and Building Materials, 29, 512-519. https://doi.org/10.1016/j.conbuildmat.2011.10.054

[4] Laborel-Préneron, A., Aubert, J.E., Magniont, C., Tribout, C. and Bertron, A. (2016) Plant Aggregates and Straw in Earth Construction Materials: A Review. Construction and Building Materials, 111, 719-734. https://doi.org/10.1016/j.conbuildmat.2016.02.119

[5] Compaore, A., Ouedraogo, B., Guengane, H., Malbila, E. and Bathiebo, D.J. (2017) Role of Local Building Materials on the Energy Behaviour of Habitats in Ouagadougou. International Journal of Applied Science, 8, 63-72.

https://doi.org/10.21013/jas.v8.n2.p3

[6] Toguyeni, D., Coulibaly, O., Ouedraogo, A., Rousse, D.R. and van, Y. (2012) Étude de l'influence de matériaux locaux isolants de toiture sur les charges de climatisation d'une maison individuelle en argile-paille. Cifem, 1, 13-93.

[7] Millogo, Y., Morel, J., Aubert, J.-E. and Ghavami, K. (2014) Experimental Analysis of Pressed Adobe Blocks Reinforced with Hibiscus cannabinus Straw. Construction and Building Materials, 52, 71-78.

https://doi.org/10.1016/j.conbuildmat.2013.10.094

[8] Malbila, E., Toguyeni, D.Y.K., Bamogo, S., Lawane, A. and Koulidiati, J. (2018) Thermophysical and Mechanical Characterization of Local Stabilized Materials Suitable for Buildings in Dry and Hot Climate. Journal of Materials Science and Surface Engineering, 6, 767-772.

[9] Ouedraogo, E., Coulibaly, O., Ouedraogo, A. and Messan, A. (2015) Caractérisation mécanique et thermophysique des blocs de terre comprimée stabilisée au papier (cellulose) et/ou au ciment. Journal of Materials and Engineering Structures, 2, 68-76.

[10] Imbga, K.B., Ouédraogo, E., Sambou, V., Kieno, F.P., Ouédraogo, A. and Bathiebo, D.J. (2018) New Materials for Thermal Insulation in Rural Construction. Current Journal of Applied Science and Technology, 29, 1-10. https://doi.org/10.9734/CJAST/2018/43786

[11] Bentchikou, M., Hanini, S., Silhadi, K. and Guidoum, A. (2007) Elaboration and Study of the Mortar Composed of Mineral Matrix and Cellulose Fibre: Thermal Conductivity in Buildings. The Canadian Journal of Civil Engineering, 34, 37-45. https://doi.org/10.1139/106-149

[12] Pagliolico, S.L., Ronchetti, S., Turcato, E.A., Bottino, G., Gallo, L.M. and De Paoli, R. (2010) Physicochemical and Mineralogical Characterization of Earth for Building in North West Italy. Applied Clay Science, 50, 439-454. https://doi.org/10.1016/j.clay.2010.08.027

[13] Lifset, R. and Eckelman, M. (2013) Material Efficiency in a Multi-Material World. Philosophical Transactions of the Royal Society A: Mathematical, Physical and Engineering Sciences, 371, 13. https://doi.org/10.1098/rsta.2012.0002

[14] Vissac, A., Bourgès, A., Gandreau, D., Anger, R. and Fontaine, L. (2017) Argiles \& biopolymères, les stabilisants naturels pour la construction en terre, CRAterre. Labex AE\&CC et l'IDEFI. 
[15] Vissac, A., et al. (2013) Recettes traditionnelles de stabilisation de la terre crue avec des composés organiques. Conférence international, Ecomatériaux de construction: Pilier de la croissance verte en Afrique, Ouagadougou, 10 au-12 juin 2013, 11.

[16] Taallah, B. and Guettala, A. (2016) The Mechanical and Physical Properties of Compressed Earth Block Stabilized with Lime and Filled with Untreated and Alkali-Treated Date Palm Straw. Construction and Building Materials, 104, 52-62. https://doi.org/10.1016/j.conbuildmat.2015.12.007

[17] Sore, S. O., Messan, A., Prud'homme, E., Escadeillasc, G. and François, T. (2018) Stabilization of Compressed Earth Blocks (CEBs) by Geopolymer Binder Based on Local Materials from Burkina Faso. Construction and Building Materials, 165, 333-345. https://doi.org/10.1016/j.conbuildmat.2018.01.051

[18] Ezbakhe, H., et al. (2001) Comportement thermique de la terre stabilisée au ciment. Revue Française de Génie Civil, 5, 505-515. https://doi.org/10.1080/12795119.2001.9692320

[19] Muntohar, A.S. (2003) Swelling and Compressibility Characteristics of Soil-Bentonite Mixtures. Dimensi Teknik Sipil, 5, 93-98.

[20] Paulus, J. (2015) Construction en terre crue: Dispositions qualitatives, constructives et architecturales-Application à un cas pratique: Ouagadougou. Liège.

[21] Gélard, D. (2005) Identification et caractérisation de la cohésion interne du matériau terre dans ses conditions naturelles de conservation. Institut National Polytechnique de Grenoble.

[22] Christine, D.A., Séraphin, D.A., Olivier, B.M. and Edjikémé, E. (2018) Effet de l'addition de fibres de coco traitées à la potasse sur les propriétés mécaniques des matériaux de construction à base d'argile-ciment. European Scientific Journal, 14, 104-116. https://doi.org/10.19044/esj.2018.v14n36p104

[23] Patil, A.D. and Attar, A.C. (2015) Compressed Stabilized Earth Blocks by Using Lime. International Journal of Engineering Research \& Technology, 4, 116-120. https://doi.org/10.17577/IJERTV4IS090204

[24] Izemmourena, O. and Guettala, A. (2014) Amélioration de la durbailité des briques de terre comprimée à base d'un sol de la région de Biskra. MATEC Web of Conference, 11, Article ID: 02001. https://doi.org/10.1051/matecconf/20141102001

[25] Huben, H. and Guillaud, H. (1990) Traité de construction en terre.

[26] Pachero-Torgal, F. and Jalali, S. (2011) Cementitious Building Materials Reinforced with Vegetable Fibres: A Review. Construction and Building Materials, 25, 575-581. https://doi.org/10.1016/j.conbuildmat.2010.07.024

[27] Morel, J., Pkla, A. and Walker, P. (2007) Compressive Strength Testing of Compressed Earth Blocks. Construction and Building Materials, 21, 303-309. https://doi.org/10.1016/j.conbuildmat.2005.08.021

[28] Morel, J., Abalo, P. and Di Benedetto, H. (2011) Essai in Situ sur blocs de terre comprimée Interprétation en compression ou traction de l'essai. Revue Française de Génie Civil, 10, 37-41.

[29] Olivier, M., Mesbah, A., El Gharbi, Z. and Morel, J.C. (1997) Mode opératoire pour la réalisation d'essais de résistance sur blocs de terre comprimée. Materials and Structures, 30, 515-517. https://doi.org/10.1007/BF02486394

[30] Meukam, P., Noumowe, A., Jannot, Y. and Duval, R. (2003) Caractérisation thermophysique et mécanique de briques de terre stabilisées en vue de l'isolation thermique de bâtiment. Materials and Structures, 36, 453-460. https://doi.org/10.1617/13802 
[31] Sharma, V., Marwaha, B.M. and Vinayak, H.K. (2016) Enhancing Durability of Adobe by Natural Reinforcement for Propagating Sustainable Mud Housing. International Journal of Sustainable Built Environment, 5, 141-155. https://doi.org/10.1016/j.ijsbe.2016.03.004

[32] Izemmouren, O., Guettala, A. and Guettala, S. (2015) Mechanical Properties and Durability of Lime and Natural Pozzolana Stabilized Steam-Cured Compressed Earth Block Bricks. Geotechnical and Geological Engineering, 33, 1321-1333. https://doi.org/10.1007/s10706-015-9904-6

[33] Miraucourt, D. (2016) Stabilisation du matériau terre crue pour application en brique de terre comprimée au Burkina Faso. 103.

[34] CRATerre-EAG (1998) Blocs de terre comprimee normes.

[35] Pacheco-Torgal, F. (2015) Introduction to Eco-Efficient Masonry Bricks and Blocks. In: Pacheco-Torgal, F., Laourenço, P.B., Labrincha, J.A., Kumar, S. and Chindaprasirt, P., Eds., Eco-Efficient Masonry Bricks and Blocks. Design, Properties and Durability, No. 55, Elsevier, Amsterdam, 1-10. https://doi.org/10.1016/B978-1-78242-305-8.00001-2

[36] Sanou, I., Seynou, M., Zerbo, L. and Ouedraogo, R. (2019) Mineralogy, Physical and Mechanical Properties of Adobes Stabilized with Cement and Rice Husk Ash. Science Journal of Chemistry, 7, 1-10. https://doi.org/10.11648/j.sjc.20190701.11

[37] Laurent, J. (2010) Propriétés thermiques du matériau terre. 8ème festivale des architectures de terre “Grains d' Isère 2010”, Villefontaine, 18 mai 2010, 41.

[38] Saidi, M., Soukaina, A., Zeghmati, B. and Sediki, E. (2018) Stabilization Effects on the Thermal Conductivity and Sorption Behavior of Earth Bricks. Construction and Building Materials, 167, 566-577. https://doi.org/10.1016/j.conbuildmat.2018.02.063

[39] Ouedraogo, M., Dao, K., Millogo, Y., Seynou, M., Aubert, J. and Ouedraogo, M. (2017) Influence des fibres de kenaf (Hibiscus altissima) sur les propriétés physiques et mécaniques des adobes. Journal de la Société Ouest-Africaine de Chimie, 43, 48-63. 


\section{Highlights}

$>$ The mineralogical and physical properties of soils have been studies and its adaptability to construction. >We characterize CSEB usual properties as construction material and its durability against water contact. $>$ We analyze the effects of fonio straw and shea butter residues incorporating into earth material. > The different results of CSEB with agricultural and biopolymers by-products on lab conditions are presented. >This study can serve as a basis for future research and applications in habitat hygrothermal and energetic behaviour study.

\section{Nomenclature}

\begin{tabular}{|c|c|}
\hline Adina & Soils Material from Dina; \\
\hline $\mathrm{A} 1 / \mathrm{A} 2$ & Compressed earth block without stabilizer \\
\hline $\mathrm{A} 1-\mathrm{CV} / \mathrm{A} 2-\mathrm{CV}$ & CSEB stabilized with $1.5 \%$ in mass of lime; \\
\hline $\mathrm{A} 1-3 \mathrm{FF} / \mathrm{A} 2-3 \mathrm{FF}$ & CSEB stabilized with $3 \%$ in mass of fonio straw \\
\hline \multicolumn{2}{|c|}{$\mathrm{A} 1-\mathrm{CV}-3 \mathrm{FF} / \mathrm{A} 2-\mathrm{CV}-3 \mathrm{FF} \mathrm{C}$} \\
\hline A1-3RL/A2-3RL & CSEB stabilized with $3 \%$ in mass of Shea butter residue \\
\hline A1-5RL/A2-5RL & CSEB stabilized with $5 \%$ in mass of Shea butter residue \\
\hline BLT & Curved laterite block \\
\hline CEB & Compressed Earth Block \\
\hline CSEB & Compressed Stabilized Earth Block \\
\hline $\mathrm{Cc}$ & Coefficient of Capillarity in $\mathrm{g} / \mathrm{cm}^{2} \cdot \min$ \\
\hline $\mathrm{Cp}$ & Specific heat mass $(\mathrm{J} / \mathrm{Kg} \cdot \mathrm{K})$ \\
\hline FF & Fonio straw; \\
\hline $\mathrm{MPa}$ & Megapascals \\
\hline $\mathrm{RBK}$ & Shea butter residue \\
\hline$R_{c}$ & Compressed resistance in $\mathrm{MPa}$ \\
\hline$R_{f}$ & Three-point bending strength in $\mathrm{MPa}$ \\
\hline$\gamma_{d}$ & Dry density in $\mathrm{g} / \mathrm{cm} 3$ \\
\hline$\omega_{o p t}$ & Optimal water content in \% \\
\hline$\lambda$ & Thermal conductivity in $\mathrm{W} / \mathrm{m} \cdot \mathrm{K}$ \\
\hline$a$ & Thermal diffusivity in $\mathrm{m}^{2} / \mathrm{s}$ ) \\
\hline$F$ & Maximal load applied to CSEB in kilonewtons $(\mathrm{kN})$ \\
\hline S & Average surface area of test faces in square centimeter $\left(\mathrm{cm}^{2}\right)$ \\
\hline 1 & Distance between the two supports in $\mathrm{mm}$; \\
\hline$b$ & Base of the right section of block in $\mathrm{mm}$ \\
\hline$\rho$ & Density in $\mathrm{kg} / \mathrm{m}^{3}$ \\
\hline$\Delta T$ & Temperature variation in ${ }^{\circ} \mathrm{K}$ \\
\hline$Q$ & Heating power in $\mathrm{W} / \mathrm{m}$ \\
\hline$t$ & Heating time in second (s) \\
\hline$B$ & Constant \\
\hline 。 & Degree angle \\
\hline
\end{tabular}

